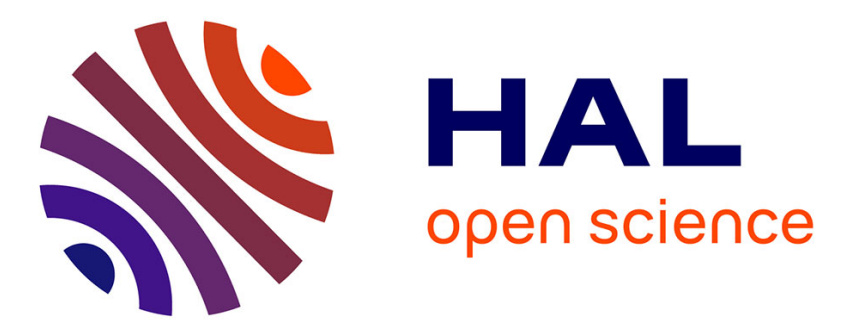

\title{
Balloon-borne observations of mid-latitude stratospheric water vapour: comparisons with HALOE and MLS satellite data
}

Gwenaël Berthet, Jean-Baptiste Renard, Mélanie Ghysels, Georges Durry, Bertrand Gaubicher, Nadir Amarouche

\section{- To cite this version:}

Gwenaël Berthet, Jean-Baptiste Renard, Mélanie Ghysels, Georges Durry, Bertrand Gaubicher, et al.. Balloon-borne observations of mid-latitude stratospheric water vapour: comparisons with HALOE and MLS satellite data. Journal of Atmospheric Chemistry, 2013, 70, pp.197 - 219. 10.1007/s10874013-9264-7 . insu-01110062

\section{HAL Id: insu-01110062 \\ https://hal-insu.archives-ouvertes.fr/insu-01110062}

Submitted on 27 Jan 2015

HAL is a multi-disciplinary open access archive for the deposit and dissemination of scientific research documents, whether they are published or not. The documents may come from teaching and research institutions in France or abroad, or from public or private research centers.
L'archive ouverte pluridisciplinaire HAL, est destinée au dépôt et à la diffusion de documents scientifiques de niveau recherche, publiés ou non, émanant des établissements d'enseignement et de recherche français ou étrangers, des laboratoires publics ou privés. 


\section{Balloon-borne observations of mid-latitude stratospheric water}

vapour: comparisons with HALOE and MLS satellite data

Gwenaël Berthet, Jean-Baptiste Renard, Mélanie Ghysels, Georges Durry,

Bertrand Gaubicher, Nadir Amarouche

Gwenaël Berthet, Jean-Baptiste Renard, Bertrand Gaubicher

Laboratoire de Physique et Chimie de l'Environnement et de l'Espace (LPC2E), UMR 7328 CNRS-

Université d'Orléans, Orléans, France

Mélanie Ghysels, Georges Durry

Groupe de Spectrométrie Moléculaire et Atmosphérique (GSMA), UMR 6089, CNRS-Université de Reims, Reims, France

Nadir Amarouche

Division Technique de l'Institut National des Sciences de l'Univers, Meudon, France

Corresponding author: Gwenael Berthet gwenael.berthet@cnrs-orleans.fr

Journal of Atmospheric Chemistry 
Abstract. We present here in situ measurements obtained between 1991 and 2011 in outervortex conditions by the ELHYSA balloon-borne frost-point hygrometer. The frost-point hygrometer profiles are used for comparisons with the satellite data from version 19 (v19) and version 3.3 (v3.3) of the HALogen Occultation Experiment (HALOE) and the Microwave Limb Sounder (MLS) respectively. Potential Vorticity mapping is applied to all data sets to remove contributions of transient tropical intrusions and polar vortex air masses and hence ensure consistent comparisons between the balloon and satellite observations. Our selected balloon in situ observations are too sparse to directly infer mid-latitude stratospheric time series for continuous comparisons with HALOE and MLS records or derive water vapour trends but can be used to validate the satellite data. A mean difference of $-0.83 \pm 1.58 \%$ ($0.04 \pm 0.07 \mathrm{ppmv}$ ) is obtained between HALOE v19 data and the balloon frost-point observations (with respect to HALOE) over the $30-80 \mathrm{hPa}$ altitude range. The ELHYSAHALOE differences appear time-dependent as already presented in the literature. The mean difference reaches $2.80 \pm 0.96 \%$ ( $0.13 \pm 0.04 \mathrm{ppmv})$ for MLS v3.3, with MLS systematically wetter than the balloon data reflecting a systematic bias between both datasets. We use our balloon data as reference to provide some information about the HALOE-MLS difference. From post-2000 ELHYSA-HALOE and ELHYSA-MLS comparisons, we find a HALOEMLS difference matching the expected bias, with MLS v3.3 6.60 $\pm 2.80 \%(0.27 \pm 0.11 \mathrm{ppmv})$ wetter than HALOE v19. From the results obtained from our balloon-satellite data comparisons, we finally discuss the issue about merging the HALOE and MLS data sets to provide stratospheric water vapour trends. 


\section{Introduction}

Water vapour amounts entering the stratosphere are largely controlled by seasonal variations of temperatures near the cold tropical tropopause resulting in the dry stratosphere (Brewer, 1949) and a pronounced seasonal cycle in tropical stratospheric water vapour illustrated by the tropical "tape recorder" (Mote et al., 1996). Meridional transport from the tropical stratosphere with a timescale of months impacts the mid-latitude water vapour content in the lower stratosphere (typically in the $150-80 \mathrm{hPa}$ range or below about $18 \mathrm{~km}$ ) as shown by satellite observations (e.g. Randel et al., 2001). Above these altitude levels, typically above $440 \mathrm{~K}(\sim 18 \mathrm{~km})$, the mid-latitude stratosphere appears to be more isolated from the tropics (Plumb, 1996) with the water vapour content expected to vary much less with altitude and time compared to the levels below.

The global budget of stratospheric water vapour has direct implications on ozone chemistry through homogeneous and heterogeneous chemical processes (Dvortsov and Solomon, 2001). Its radiative effects are particularly large in the upper troposphere and lower stratosphere (UTLS) region (Rind et al., 1991; Forster and Shine, 1999). It is then important to derive and understand trends in stratospheric water vapour. The longest continuous record has been established using long-term regular soundings by the NOAA balloon-borne frostpoint hygrometer over Washington, D.C., from 1964 to 1976 and over Boulder, Colorado, from 1980 onwards. This dataset, widely used in the scientific community, has shown a general increase in the mid-latitude stratospheric water vapour content of $1-1.5 \%$ per year since the 1960s (Oltmans and Hofmann, 1995; Oltmans et al., 2000; Rosenlof et al., 2001) with distinct trend values characterized by shorter-term increases or decreases depending on the selected period between 1980 and 2010 (Hurst et al., 2011). Such a trend could have significant implications on the atmosphere with in particular a contribution to long term 
global climate warming as suggested by global model simulations (Forster and Shine, 2002; Solomon et al., 2010). Additionally, an increase of the stratospheric water vapour content could contribute to an increase in the rate of polar ozone destruction through an intensification of the formation of polar stratospheric clouds and perturbations in the gas phase chemistry (Kirk-Davidoff et al., 1999; Shindell, 2001).

However, the stratospheric water vapour trend does not match with long-term changes of tropical tropopause temperatures inferred from radiosondes over the $\sim 1980-2000$ period (Zhou et al., 2001; Seidel et al., 2001) and no obvious atmospheric process has been found to undoubtedly attribute its origin and amplitude (Oltmans and Hofmann, 1995; Kley et al., 2000). Only about one third of the detected water vapour positive trend can be attributed to the anthropogenic increase in methane which is the major in situ source of stratospheric water vapour (le Texier et al., 1988; Rohs et al., 2006). Various processes have been suggested to potentially contribute to the remaining change in the stratospheric water vapour content at a global scale such as variations in ENSO (El Niño/Southern Oscillation) activity (Bonazzola and Haynes, 2004; Fueglistaler and Haynes, 2005), modulation by Quasi-biennial Oscillation (QBO) (Randel et al., 2004), the interplay between ENSO and QBO modes (Liang et al., 2011) and possible changes in the residual circulation related to the latitude broadening of the tropical upwelling (Zhou et al., 2001). Other mechanisms such as volcanic eruptions (Considine et al., 2001; Joshi and Shine, 2003), multi-decadal increases in anthropogenic emissions of $\mathrm{SO}_{2}$ in Southern and Eastern Asia (Notholt et al., 2005) or the increasing aerosol content from tropical biomass burning (Sherwood, 2002) have been invoked. Most of the above-mentioned mechanisms would potentially affect the water vapour entering the stratosphere in the tropics with subsequent effect on higher latitudes.

Only partial agreement is observed between HALOE data (Russell et al., 1993) and the NOAA balloon record near Boulder in the lower stratosphere in terms of seasonal and 
interannual variations though the decadal increase observed in the balloon record appears to be of less amplitude in HALOE data for 1992-2001 (Randel et al., 2004). Despite a reevaluation process of the NOAA frost-point hygrometer observations (Scherer et al., 2008), differences remain between balloon data and HALOE in terms of trends and variability of stratospheric water vapour. Both HALOE and balloon time series show in 2001 a sudden drop in stratospheric water vapour amounts (about -0.4 ppmv in HALOE data) consistent with a decrease in the tropical tropopause temperature trend of about $-1 \mathrm{~K}$ (Randel et al., 2006). Persistent low values of water vapour are observed for a period of about 4 years but with still some differences between HALOE and NOAA balloon records (Scherer et al., 2008). The differences between these specific measurements reflect the still-unexplained discrepancies among various types of instruments implemented onboard aircraft, balloon and satellite platforms (see Kley et al., 2000). None of the instruments involved in the extensive comparisons reported by Kley et al. (2000) have been considered as a standard or reference for the measurement of stratospheric water vapour. As a consequence, inferring reliable water vapour time series by merging various sources of data to quantify water vapour variations at various time scales (seasonal, interannual and long-term) appears to be somewhat complicated (Fueglistaler and Haynes, 2005). To do so, biases between stratospheric water vapour observations, such as between satellite data (e.g. Lambert et al. 2007; Montoux et al. 2009), but also the time drifts of these differences must be investigated.

The aim of this paper is to provide further intercomparisons between independent balloon observations from a frost-point hygrometer and the HALOE and MLS satellite data. We use here in situ measurements of stratospheric water vapour performed by the ELHYSA (French acronym for "Etude de L’HYgrométrie StrAtosphérique”, formerly referred as "LMD cryogenic frost-point hygrometer" such as in Kley et al., 2000). The ELHYSA and satellite vertical profiles are sorted out using Potential Vorticity (PV) fields to get mid-latitude 
stratospheric conditions. Balloon-satellite comparisons matching this dynamical criterion are analyzed over the 1991-2011 period.

\section{Instruments}

\subsection{The ELHYSA frost-point hygrometer}

\subsubsection{Instrument description}

The ELHYSA frost-point hygrometer (Ovarlez, 1991; Ovarlez and Ovarlez, 1994) has been operating for about 20 years onboard balloon platforms (Zero-pressure balloons and Infrared Montgolfieres) or aircrafts to study various atmospheric humidity conditions from the UTLS to the stratosphere. The instrument has been particularly involved in various international campaigns for satellite validation (e.g. Pruvost et al., 1993; Kansawa et al., 2002), validation of meteorological analyses (Ovarlez et al., 2000), studies of tropical cirrus clouds (e.g. Jensen et al., 2001; Ovarlez et al., 2002), polar vortex dehydration processes (Schiller et al., 2002), polar stratospheric cloud microphysics (e.g. Voigt et al., 2000), and stratospheric dynamics (Teitelbaum et al., 1994; Orsolini et al., 1998).

This type of instrument is considered as a Transfer Standard in the field of the Metrology of humidity and is based on the so called chilled mirror technique similarly to other frost-point hygrometers (Oltmans and Hofmann, 1995; Vömel et al., 2007a). The ambient air flow circulates over a cooled mirror onto which is formed a layer of condensate. The temperature of the cooled mirror, directly measured by an embedded thermistor, matches the frost or dew point temperature of the air in contact with the mirror. Dew or white frost is 
optically detected by a photodiode which is sensitive to the infrared light emitted by a LED. The incident light on the mirror surface is scattered by the condensate layer, reducing the specular reflection and the signal on the photodiode with respect to the signal from a bare mirror. The decreased photodiode signal is maintained by a feedback loop which controls the heater and sustains the mirror temperature at the ambient frost-point or dew point temperature. The cold source was a Peltier device until 1993 and was replaced by a cryogenic cooling system in 1994. A Peltier device has a longer regulation period than a cryogenic system. Thus, the cryogenic system is more sensitive to local changes in the water vapour content having strong vertical gradients. On the other hand, laboratory calibrations and comparisons with various observations (such as those available in the literature) have shown that this technical change has no influence on the retrieval of the global values of water vapour mixing ratios.

In-flight observations are conducted after sunset during balloon slow descent to avoid possible contamination by outgassing of water vapour from the balloon envelope located above the instrument (conditions likely to be encountered during balloon ascent).

\subsubsection{Measurement uncertainty and stability}

The dominant source of uncertainty corresponds to the feedback loop stability, i.e. its ability to sustain a constant ice layer on the mirror. This process results in oscillations around the true frost point with a period of about $15 \mathrm{~s}$ for stratospheric conditions and a maximum standard deviation of about $\pm 0.9^{\circ} \mathrm{C}$. For ELHYSA, the estimation of frost point determination uncertainty due to the feedback loop is less than $0.5^{\circ} \mathrm{C}$ (Ovarlez, 1991). Laboratory calibrations are regularly conducted on a calibration bench to check the stability of the feedback loop. The hygrometer is connected to the test bench which is set to pressure values 
of 100 and $20 \mathrm{hPa}$ reproducing the conditions in the lower and middle stratosphere respectively. Given amounts of water relevant for the stratospheric conditions are injected into the system. Frost point temperatures as low as $-95^{\circ} \mathrm{C}$ can be reached with the bench and values at which frost points are obtained on the hygrometer mirror are compared to the expected value. The feedback loop is operated by a proportional integral derivative (PID) controller with tuneable parameters to properly control the frost formation on the mirror by driving the mirror heater, as typically done for frost point hygrometers (Vömel et al., 2007a). Then, prior to each flight, this procedure allows for a careful adjustment of the mirror temperature control loop, if necessary, and has resulted in a reproducible uncertainty of less than $0.5^{\circ} \mathrm{C}$ even for oscillations of about $\pm 1^{\circ} \mathrm{C}$ (Vömel et al., 2007a) for the whole ELHYSA operational period considered in this study.

Another term of uncertainty is the measurement of the mirror temperature provided by the embedded thermistor. The thermistor is calibrated by a Pt100 platinum temperature sensor itself calibrated with an accuracy better than $0.02^{\circ} \mathrm{C}$ through national standards certified in France by the Laboratoire National de Métrologie et d'Essais (LNE). Coefficients derived from several measured calibration points are used to convert resistance to temperature values in the whole range from $-95^{\circ} \mathrm{C}$ to $+25^{\circ} \mathrm{C}$. This results in a systematic error lower than $0.05^{\circ} \mathrm{C}$ for all mirror temperatures in this range.

The structure of the water ice at very low temperatures, i.e. below $200 \mathrm{~K}$, may exist both in the hexagonal and cubic crystal feature which could affect the frost point measurements if the ice deposit on the mirror was in the cubic phase instead of the common hexagonal phase (Vömel et al., 2007a). However, for all ELHYSA data used in this study, the frost point regulation on the mirror was set off at temperatures above $200 \mathrm{~K}$ for which hexagonal ice dominates. We therefore exclude any bias on the determination of the frost point temperature from the presence of cubic ice on the mirror. 
For stratospheric conditions where ice is the condensate on the mirror, the Goff-Gratch equation is used to derive the partial pressure of water vapour from the frost point temperature measurements (Goff and Gratch, 1964). The mixing ratio is deduced by dividing water vapour partial pressure by the pressure of dry air measured using a highly-accurate Paroscientific sensor. The pressure sensor accuracy is of about $0.1 \mathrm{hPa}$ as stated by Paroscientific and remains stable owing to regular calibration in the laboratory (in particular by LNE). This uncertainty has a negligible effect on the inferred mixing ratio for the altitude range on which focuses our study (30-80 $\mathrm{hPa}$ corresponding to $\sim 24-18 \mathrm{~km})$. The various sources of uncertainty on the frost point temperature measurement described above and on the associated water vapour partial pressure calculated by from Goff-Gratch equation leads to mixing ratio measurement uncertainty of $5 \%$ for stratospheric conditions.

\subsubsection{In-flight comparisons with other instrumentation}

In-flight comparisons between instruments are valuable to investigate accuracy issues as recommended by the SPARC (Stratospheric Processes and their Role in Climate) assessment of water vapour (Kley et al., 2000) in particular for in situ instruments. The PicoSDLA- $\mathrm{H}_{2} \mathrm{O}$ tunable laser diode spectrometer measures water vapour in the $2.63 \mu \mathrm{m}$ spectral region by absorption spectroscopy (Durry et al., 2008). The sensor has been developed with the support of the CNRS and of the French space agency (CNES) and it was test-flown under a stratospheric balloon in 2007 at Aire-sur-1'Adour (France). The PicoSDLA- $\mathrm{H}_{2} \mathrm{O}$ sensor was later involved in several balloon campaigns in northern Sweden $(2010,2011)$ and in Brazil $(2008,2012)$. Its principle deals with a laser diode $(2.63 \mu \mathrm{m})$ and a InAs photodiode (Judson Inc.) which are separated by a 1-m path length in ambient air. The laser beam is partially absorbed by ambient $\mathrm{H}_{2} \mathrm{O}$ molecules. The absorption spectrum is then 
stored onboard. Considering the achieved signal-to-noise ratio in the spectra, the uncertainties on the atmospheric pressure (from Paroscientific pressure gauge) and temperature (from VIZ thermistors) measurements, on the spectroscopic parameters as well as on the concentration retrieval process, the uncertainty on stratospheric water vapour mixing ratios has been found to be within $5.5 \%$.

A common balloon flight with the ELHYSA and PicoSDLA- $\mathrm{H}_{2} \mathrm{O}$ instruments was conducted from the Kiruna/Esrange (Northern Sweden, $67.9^{\circ} \mathrm{N}, 21.1^{\circ} \mathrm{E}$ ) launching base on 12 March 2011. The comparison presented in Figure 1 corresponds to the descent of the balloon (from about 23 to $17 \mathrm{~km}$ ) during night-time and avoids the effect of water vapour outgassing from the balloon envelope. On average mixing ratios recorded by PicoSDLA- $\mathrm{H}_{2} \mathrm{O}$ are $0.8 \pm 1.2 \%(0.04 \pm 0.06 \mathrm{ppmv})$ lower than ELHYSA with a maximum difference of $3.6 \%(0.2$ ppmv) at $36.4 \mathrm{hPa}(21.5 \mathrm{~km})$. The agreement is well within the instrumental uncertainties.

Overall, the features on the vertical profiles, related to the location of the in situ observation with respect to the vortex edge position, match well for the two instruments. The small altitude difference in the position of the vertical features may be attributed to a slight time lag (of a few seconds at maximum) of the frost-point hygrometer due to the feedback loop controller which regulates the mirror temperature to sustain a frost layer on its surface (Vömel et al., 2007c). This time lag is altitude dependent as a result of the varying frost-point temperature profile and corresponds to a vertical shift varying from about $20 \mathrm{~m}$ to less than $100 \mathrm{~m}$ due to the balloon slow descent rate of $4 \mathrm{~m} \cdot \mathrm{s}^{-1}$.

Basically, this comparison indicates that there are no notable differences between the ELHYSA frost-point hygrometer and PicoSDLA- $\mathrm{H}_{2} \mathrm{O}$ spectrometer measurements below 30 $\mathrm{hPa}$. 


\subsection{Satellite data: HALOE and MLS}

\subsubsection{HALOE}

HALOE aboard the Upper Atmosphere Research Satellite (UARS) operated between October 1991 and November 2005. HALOE is a solar occultation instrument measuring mixing ratio vertical profiles of several trace gases including water vapour (Russell et al., 1993; Harries et al., 1996). Observations are made in the infrared part of the electromagnetic spectrum (between 2.45 and $10 \mu \mathrm{m}$ ). For water vapour the vertical profiles extend from about $10 \mathrm{~km}$ (approximately the tropopause level of each area) to $80 \mathrm{~km}$ with vertical resolution of about $2 \mathrm{~km}$. The observation geometry of HALOE results in about 15 sunrises and 15 sunsets daily with nice longitudinal coverage on two latitude circles each day, one for the sunrise locations and the other one for the sunset locations. Latitude coverage of HALOE is from about $80^{\circ} \mathrm{N}$ and $80^{\circ} \mathrm{S}$ over the course of a year but varies continuously from one month to another. Approximately one month is necessary to sample the latitude range $60^{\circ} \mathrm{N}-60^{\circ} \mathrm{S}$ and about six weeks to achieve a global coverage. This provides extensive spatial coverage for the estimation of the water vapour trend at mid-latitudes, in the tropical entry region of water vapour or at a global scale. In our analysis, sunrise and sunset data are combined and we use the v19 retrieval product obtained from http://haloe.gats-inc.com/download/index.php. We have made the choice to use v19 because this version has been widely published and available in the literature. The error estimates provided in the HALOE data files include random components due to noise and altitude dependent quasi-systematic errors due to uncertainties in corrections of aerosol effects. A dry bias of about 5\% in HALOE water vapour data has 
been highlighted in the stratosphere (between 1 and $100 \mathrm{hPa}$ ) from extensive intercomparisons with aircraft and balloon measurements (Kley et al., 2000). As mentioned by Randel et al. (2006) from a private communication by J. M. Russell III (2005), the HALOE water vapour spectral signal has shown robust long-term stability with changes of only $0.5 \%$ since launch. Also, the self-calibrating characteristics of HALOE minimize the effect of instrumental drift throughout its 14-year period of observation.

\subsubsection{MLS}

The MLS instrument is part of the EOS Aura spacecraft launched in August 2004 (Waters et al., 2006). MLS detects Earth thermal emission lines from many trace gases at microwave-far infrared wavelengths. The standard $\mathrm{H}_{2} \mathrm{O}$ product used in this paper is retrieved from the radiances measured at $183 \mathrm{GHz}$. MLS looks forward from Aura in a sunsynchronous near polar orbit with almost global latitude coverage from $82^{\circ} \mathrm{S}$ to $82^{\circ} \mathrm{N}$ and scans the Earth's limb vertically at night and day from the ground to about $90 \mathrm{~km}$ every $24.7 \mathrm{~s}$. Vertical scans are synchronized to the Aura orbit leading to retrieved profiles at the same latitude every orbit. There are 240 limb scans per orbit providing close to 3500 profiles per day spaced at $1.5^{\circ}$ intervals. The vertical resolution is about $3-4 \mathrm{~km}$ in the stratosphere and the horizontal resolution is mostly between 200 and $300 \mathrm{~km}$. We focus here on version 3.3 since this is the latest extensive version available at the time of this study. Extensive assessment has been conducted for MLS version 2.2 (v2.2) $\mathrm{H}_{2} \mathrm{O}$ product through validation studies using various independent instruments aboard satellites, aircrafts and balloons (Lambert et al., 2007; Read et al., 2007; Vömel et al., 2007b). For MLS v2.2 $\mathrm{H}_{2} \mathrm{O}$ data, the single-profile precision is about $0.2-0.3 \mathrm{ppmv}(4-9 \%)$ in the stratosphere and the accuracy is estimated to be $0.2-0.5 \mathrm{ppmv}(4-11 \%)$ for the pressure range $68-0.01 \mathrm{hPa}$ (Lambert et al., 
2007). This precision is not achieved in the lower stratosphere and upper troposphere region with values of $10-20 \%$ from 121 to $83 \mathrm{hPa}$ (Read et al., 2007). MLS v3.3 $\mathrm{H}_{2} \mathrm{O}$ product is expected to be about $0.2-0.3 \mathrm{ppmv}$ wetter than v2.2 in the pressure range $83-0.1 \mathrm{hPa}$ (Livesey, 2011). For pressures greater than $21 \mathrm{hPa}$, the precisions of two versions are nearly identical.

The MLS retrieval approach can be found in Livesey et al. (2006). Since MLS and in situ instruments like ELHYSA have hugely different vertical resolutions it is recommended to degrade the high-resolution profile using both the vertical averaging kernels of $\mathrm{H}_{2} \mathrm{O}$ MLS data and the MLS forward model smoothing function (Read et al., 2007; Vömel et al., 2007b) for validation purpose. However applying the MLS averaging kernels is a rather heavy process. In our case a more simple least square fit method is an acceptable approach at least to investigate consistencies between such sets of data as recommended for users of v3.3 MLS data (Livesey, 2011) and done by Froidevaux et al. (2008) for MLS ozone validation. Also, the three quality metrics which are available for each MLS profile to characterize the quality of the data (Lambert et al., 2007) are used accordingly in the following to remove profiles considered as inappropriate for scientific studies. The MLS data are available from the NASA

Goddard Earth Sciences Data and Information Services Centre (http://mirador.gsfc.nasa.gov/index.shtml).

\section{Balloon frost-point and satellite data intercomparisons}

\subsection{Data selection for mid-latitude conditions}

In the following we will focus on data available within the Northern mid-latitude regime, namely between the subtropics and the polar fronts, because it is the geographic area 
where the published stratospheric water vapour trends have been established. Also, focussing on mid-latitude conditions allows us to minimize the effects of strong gradients of stratospheric chemical species (including water vapour) which are likely to bias remote sensing observations performed within a recurrently perturbed dynamical regime like the arctic polar vortex (Swartz et al., 2006; Berthet et al., 2007a). Accordingly, the ELHYSA frost-point and satellite sets of data presented in the following have been sorted out to achieve these conditions for balloon-satellite comparisons as robust as possible.

The selection method used is based on PV fields which has already been used for comparisons of balloon and satellite (including HALOE) instruments (Michelsen et al., 2002; Sugita et al., 2006) and have been found to be correlated with water vapour (e.g. Dethof et al., 1999; Schiller et al., 2002). A justification of using PV mapping rather than simple zonal means on a given mid-latitude range is that zonal averaging is likely to encompass airmasses of different meteorological signature, in particular those from an elongated or leaking Arctic vortex. To support this analysis, we use the MIMOSA (French acronym for 'Modèle Isentropique de transport Mesoéchelle de l'Ozone Stratosphérique par Advection') highresolution advection model for PV. Advection calculations are based on the ECMWF (European Centre for Medium-Range Weather Forecasts) horizontal wind component to provide PV fields on isentropic surfaces. The implementation of MIMOSA is described in details in Hauchecorne et al. (2002). PV mapping computed from ECMWF 45-year reanalysis (ERA-40) data available from the British Atmospheric Data Centre (BADC, see http://badc.nerc.ac.uk/) has also been used for the ELHYSA flights before 1998.

All ELHYSA balloon data were obtained from two different launching sites, Aire sur 1'Adour (Southern France, $43.7^{\circ} \mathrm{N}, 0.3^{\circ} \mathrm{W}$ ), and Kiruna/Esrange (Northern Sweden, $67.9^{\circ} \mathrm{N}$, $\left.21.1^{\circ} \mathrm{E}\right)$. The high-latitude location of the Kiruna site is statistically exposed to the presence of the Arctic polar vortex depending on the period of year. The location of the Aire sur l'Adour 
mid-latitude site is also likely to be affected by polar vortex filaments or remnants in the wintertime and springtime but also by tropical intrusions (Durry et al., 2002). PV fields are used to investigate the occurrence of all these phenomena and subsequently exclude balloon and satellite data obtained within vortex, filament airmasses and tropical intrusions as illustrated on Figure 2. We have selected values of PV which are clearly much stronger than the values expected for the tropopause region and lowermost stratosphere, i.e. between 2 and $\sim 10$ pvu (e.g. Berthet et al. 2007b), to ensure that our data are not affected by air masses stemming from these regions. For instance, for the $510 \mathrm{~K}$ potential temperature level $(\sim 21$ $\mathrm{km}$ ), mid-latitude conditions are satisfied for PV ranging from 30 to $40 \mathrm{pvu}$, which means that tropical and vortex air are flagged with $\mathrm{PV}<30 \mathrm{pvu}$ and $\mathrm{PV}>40$ pvu respectively. Twelve ELHYSA profiles or parts of profiles corresponding to mid-latitude conditions and performed since 1991 (Table 1) have been selected. For some of these profiles, some vertical layers have to be excluded as shown in Figure 3 where the position of the vortex barrier is represented on a high-resolution vertical profile of water vapour recorded by the ELHYSA hygrometer. It is shown that the transition of the vertical sounding to inner vortex air masses results in a sharp increase of about $1 \mathrm{ppmv}$ of water vapour resulting from the downward transport of higher amounts of water vapour produced by methane oxidation (e.g. Michelsen et al., 2002). Rejection of some particular vertical layers for a given flight has also been done in case of tropical intrusions within these layers. As an example, the presence of dehydrated air resulting from a tropical intrusion was well documented by Durry et al. (2002) on October 2001 from the Aire sur l'Adour French site using the predecessor of the PicoSDLA-H2O spectrometer and the ELHYSA hygrometer six days apart. The occurrence of a tropical intrusion is unambiguously reflected by local decreases in the water vapor content of $0.5 \mathrm{ppmv}$ in the balloon profiles between about 50 and $40 \mathrm{hPa}$. 
Then, satellite data have been sorted out as coincident (in space and time) as possible to the balloon records. The coverage of HALOE measurements is constrained by the EarthSun geometry which limits the sampling rate of a given geographical area at a specific period. Taking into account this constraint, we had to consider HALOE data between 0 and 15 days apart from the balloon record and spanning the $40-70^{\circ} \mathrm{N}$ latitude range with no restriction on longitude. Within this restricted area and period, PV fields have been used to geographically reject HALOE profiles affected by vortex air and tropical intrusions and the selected profiles have been averaged. This has allowed us to get the common characteristics of the northern mid-latitude water vapour at the given period of the balloon observations. Note that for the case of the 7 October 2005 flight no HALOE data are available to meet the time coincidence criterion which has consequently been extended to 23-25 days apart from the balloon observations.

MLS offers better time sampling than HALOE resulting in a temporal coincidence range of 12 hours before and after the time of the balloon flight (which means both day and night contributions in the MLS profiles). MLS almost global sampling allows us to make direct profile matching with the balloon profile based on PV coordinates. Note however that comparison cases between the frost-point and MLS for coincidences too close to the vortex edge have been excluded as a result of the possible biases likely to affect remote-sensing observations crossing strong PV (and associated chemical species concentration) gradients (Berthet et al., 2007a). Then, within these restricted PV-based areas MLS profiles have been averaged on a daily basis.

In the UTLS, water vapour amounts are strongly variable making comparisons between various instruments more difficult (Kley et al., 2000). Figure 4 illustrates the greater variability of water vapour from averaged coincident ELHYSA and HALOE data below the $80 \mathrm{hPa}$ level $(\sim 440 \mathrm{~K}, \sim 18 \mathrm{~km})$ where variations of about 1 ppmv are observed. This reflects 
the strong "ventilation" characterizing the mid-latitude lower stratosphere (e.g. Berthet et al., 2007b). In Figure 4, seasonal variation amplitudes of only a few tenths of ppmv are observed above the $80 \mathrm{hPa}$ level, reflecting the stronger isolation from the tropics in this part of the stratosphere. Error bars represent the 1-sigma standard deviations which are of 0.2-03 ppmv above the $80 \mathrm{hPa}$ level and 0.6-0.7 ppmv below. The vertical behavior shown on Figure 4 is closely related to the results of Hurst et al. (2011) who have highlighted the strong impact of seasonal variations of water vapour on its mid-latitude vertical profiles for altitude levels below the stratospheric "overworld" (see their Figure 2). Another point deals with heavy levels of aerosol loadings produced by volcanic eruptions and which are likely to generate biased water vapour profiles in the satellite data sets in the lower stratosphere (Hervig et al., 1995) where most of the sulfate aerosols are located (e.g. Junge et al., 1961; Renard et al., 2008). As a consequence, in the following we will focus on observations above the $80 \mathrm{hPa}$ altitude level which will presumably attenuate the spread of the intercompared data.

\subsection{Results}

\subsubsection{Vertical profiles}

Figure 5 presents examples of comparisons between the ELHYSA frost-point hygrometer and HALOE v19 averaged vertical profiles for the two balloon launching sites from the method described above. An intrusion of dehydrated tropical air has been identified between 47 and $60 \mathrm{hPa}$ for the 5 May 1999 flight in France. Excluding this layer, the frostpoint hygrometer and HALOE (with respect to ELHYSA) agree to within $-0.91 \pm 1.76 \%$ ($0.04 \pm 0.08$ ppmv) on average (at the $1-\sigma$ level) above $80 \mathrm{hPa}$. For the case on 10 August 1998 in summer high latitudes, the agreement between the frost-point hygrometer and HALOE is of $+0.80 \pm 1.91 \%(+0.04 \pm 0.09 \mathrm{ppmv})$ on average above $80 \mathrm{hPa}$. Together with the comparison 
shown in Figure 4 no clear dry or moist bias is apparent in the relationship between the balloon and HALOE data above $80 \mathrm{hPa}$. Comparisons of vertical profiles between the ELHYSA frost-point hygrometer and MLS v3.3 product are shown on Figure 6. ELHYSA and MLS (with respect to ELHYSA) agree to within $-1.19 \pm 1.64 \%(-0.06 \pm 0.08 \mathrm{ppmv})$ above $80 \mathrm{hPa}$ (at the 1- $\sigma$ level) for the case of 7 October 2005 at mid-latitudes. For the 4 April 2010 mid-latitude profile MLS $\mathrm{H}_{2} \mathrm{O}$ is smaller than the frost-point hygrometer by $-3.18 \pm 0.67 \%$ ($0.14 \pm 0.03 \mathrm{ppmv}$ ) above $80 \mathrm{hPa}$.

To examine the possible biases between the frost-point hygrometer and the satellite instruments we have represented the coincident comparisons in vertical bins. In the literature several works present comparisons of water vapour observations or trends in vertical bins (Oltmans and Hofmann, 1995; Oltmans et al., 2000; Scherer et al., 2008; Hurst et al., 2011). In our study, 4 vertical pressure levels have been chosen to average the balloon and satellite data, 30-40, 40-50, 50-65 and 65-80 hPa corresponding to 24-22, 22-20, 20-19 and 19-18 km altitude levels respectively. Such vertical averaging on the high-resolution ELHYSA vertical profiles allows us firstly to smooth out small scale structures that may be not resolved by the PV fields and secondly to reduce the time lag instrumental issue emphasized from the in situ comparison between the frost-point hygrometer and the spectrometer. The vertical resolution of HALOE data provides 4 to 7 points to be averaged per pressure bin. The four selected pressure bins correspond well to the vertical resolution of MLS with at least one MLS point per pressure bin.

\subsubsection{Comparisons in vertical bins}

Figure 7 presents the comparisons between balloon and satellite averaged data for the 4 selected pressure ranges over the 1991-2011 period. Figure 8 presents the results for the 30- 
$80 \mathrm{hPa}$ range. For the 1991 case, greater standard deviations are visible for the four HALOE points possibly resulting from anomalies in HALOE v19 data. Actually, corrections have been applied to HALOE v19 data from mid-1992 to reduce the effect of the stratospheric aerosol loading strongly enhanced after the Mount Pinatubo eruption in 1991 (e.g. Russell et al., 1996) and causing anomalously large water vapour mixing ratios in the HALOE retrievals (Hervig et al., 1995). However since the ELHYSA and HALOE observations at mid-latitudes agree well for the November 1991 balloon flight we assume it is worth keeping this data though Randel et al. (2004) and Scherer et al. (2008) have omitted HALOE data prior to mid1992 in their stratospheric water vapour trend estimations. For the 1993 case, a standard deviation of 0.2 ppmv is apparent in HALOE data which might originate from the effect of Pinatubo aerosols on HALOE water vapour retrieval or from the inadequate quality of the 1993 meteorological fields used to drive the PV model. For the 2001 case at $65-80 \mathrm{hPa}$ the HALOE water vapour mixing ratio is 0.2 ppmv lower than the ELHYSA record which might be the result of vertical layers "spoiled" by tropical air or mixed air (Durry et al., 2002) not captured by the PV fields used to select HALOE data. 2005 is an interesting case since it is the only year for which we can benefit from both HALOE and MLS data sets.

What can be seen on Figure 7 and Figure 8 for the 2005 comparison is a good agreement between the balloon and satellite data for the four pressure levels. Nevertheless, for the 2005 case, the expected bias between MLS v3.3 and HALOE v19 $\mathrm{H}_{2} \mathrm{O}$ products is not apparent. From the validation work of $\mathrm{MLS}_{2} \mathrm{O}$ by Lambert et al. (2007) a bias of 2-10\% ( 0.1-0.4 ppmv) over the 68-1.5 hPa range has been reported between MLS v2.2 and HALOE v19 data with MLS wetter than HALOE. The discrepancy between MLS and HALOE is expected to be even stronger when HALOE v19 is compared to MLS v3.3 since MLS v3.3 is 0.2-0.3 ppmv ( 4\%) wetter than v2.2 in the 83-0.1 hPa range (Livesey, 2011). We have represented time series of HALOE v19 and MLS v3.3 monthly means on the same plot to 
illustrate the bias between both instruments for their August 2004-November 2005 overlapping period over the $30-80 \mathrm{hPa}$ vertical range (Figure 9). MLS v3.3 appears systematically higher than HALOE v19. On average, we find a statistically significant mean difference of $6.60 \pm 2.80 \%(0.27 \pm 0.11 \mathrm{ppmv})$ with respect to HALOE which is in agreement with the difference expected associating the results of Lambert et al. (2007) and Livesey (2011). Mean differences (individual differences with their standard deviations at the 1- $\sigma$ level) ranging from $4.70 \pm 2.40 \%(0.20 \pm 0.10 \mathrm{ppmv})$ to $7.30 \pm 6.20 \%(0.27 \pm 0.22 \mathrm{ppmv})$ are found between MLS v3.3 and HALOE v19 $\mathrm{H}_{2} \mathrm{O}$ for the four vertical levels. The calculated bias appears rather similar for all the vertical ranges, reflecting its systematic feature. Our HALOE-MLS comparison for the single 2005 case highlights differences of only $0.60 \%(0.03$ ppmv) on average for $30-80 \mathrm{hPa}$. The longer time lag between the balloon and HALOE observations (and therefore between HALOE and MLS), which have been taken 25 days apart due to a lack of available HALOE observations in October 2005, could result in a somewhat fortuitous agreement between HALOE and MLS.

Table 2 summarizes the calculated differences (at the 1- $\sigma$ level) between the satellite data and ELHYSA observations (with respect to the ELHYSA hygrometer) for all the considered vertical bins on average for the considered comparison periods. Mean differences (using the mean values of water vapour mixing ratios of ELHYSA and HALOE) of $0.08 \pm 2.39 \%(0.00 \pm 0.11 \mathrm{ppmv}),-0.07 \pm 0.93 \%(0.00 \pm 0.04 \mathrm{ppmv}),-0.92 \pm 2.49 \% \quad(-0.04 \pm 0.11$ ppmv) and $-1.62 \pm 2.58 \%(-0.07 \pm 0.11 \mathrm{ppmv})$ are obtained between HALOE and the frost-point hygrometer for the 30-40, 40-50, 50-65 and 65-80 hPa levels respectively. These values, not statistically different from zero, reflect that no systematic bias is apparent between the ELHYSA hygrometer and HALOE from the 9 comparison cases reported in Figure 7 with about half of the HALOE mixing ratios higher than the balloon data. Another way to compare HALOE and ELHYSA observations is to calculate the average of the absolute differences 
between both datasets to disregard the sign variation of the differences observed throughout the 9 comparison cases. We obtain values of $2.00 \pm 1.02 \%(0.10 \pm 0.04 \mathrm{ppmv}), 0.82 \pm 0.24 \%$ $(0.04 \pm 0.01 \mathrm{ppmv}), 2.01 \pm 1.54 \%(0.09 \pm 0.07 \mathrm{ppmv}), 2.52 \pm 1.53 \%(0.10 \pm 0.06 \mathrm{ppmv})$ for the $30-$ 40, 40-50, 50-65 and 65-80 hPa levels respectively (Table 2).

For the whole $30-80 \mathrm{hPa}$ range, all ELHYSA data are within the 1-sigma standard deviation bars of the HALOE observations (Figure 8) resulting in statistically insignificant mean differences of $-0.83 \pm 1.58 \%(-0.04 \pm 0.07 \mathrm{ppmv})$ between the satellite and the hygrometer on average between 1991 and 2005 (Table 2). Calculations of mean absolute differences give values of $1.48 \pm 0.90 \%(0.07 \pm 0.04 \mathrm{ppmv})$. For comparison, the results of Scherer et al. (2008) (see their Figure 1) show more pronounced differences between HALOE data and the reevaluated observations by the NOAA balloon-borne hygrometer over the 1992-2005 period, with a mean difference of about $-2.7 \%$ and a mean absolute difference around $4 \%$ (with respect to the hygrometer) in the 580-620K vertical range (about $30-23 \mathrm{hPa}$ correspondingly). Their comparisons reveal good agreement between the NOAA hygrometer and HALOE only in 1992, 1995 and between 1998 and 2000. Interestingly, the results of Scherer et al. (2008) show increasing differences between HALOE and the NOAA hygrometer after 2000 with the satellite data systematically lower. This feature may also be reflected in the HALOEELHYSA comparison in Figure 8 since we calculate an increased HALOE-ELHYSA difference (using the mean values of water vapour mixing ratios of ELHYSA and HALOE) of $-2.47 \pm 0.88 \%(-0.11 \pm 0.03 \mathrm{ppmv})$ if we take only into account the post-2000 comparison cases (excluding the 2005 case). These results might actually indicate an instrumental drift for HALOE yet stated to be stable throughout its operational period (Randel et al., 2006). It should be noted that the results of both studies are not fully comparable since firstly Scherer et al. (2008) have focussed on higher and lower vertical levels than in our study (with in particular larger balloon-satellite disagreement for the lowermost stratosphere levels) and 
secondly their comparisons are shown using 12-month running means. Our result indicates that sparse observations of stratospheric water vapour mixing ratios by different types of instruments with different resolutions compare well provided that a suitable data selection method is used.

The comparison between MLS and the frost-point hygrometer (Figure 7) result in mean differences of $3.32 \pm 1.17 \% \quad(0.16 \pm 0.05$ ppmv $), 2.75 \pm 0.54 \% \quad(0.13 \pm 0.02 \mathrm{ppmv})$, $2.28 \pm 2.43 \%(0.10 \pm 0.11 \mathrm{ppmv})$ and $2.69 \pm 1.05 \%(0.12 \pm 0.05 \mathrm{ppmv})$ (here again with respect to the hygrometer) for the 30-40, 40-50, 50-65 and 65-80 hPa levels respectively (Table 2). From these values, clearly less fluctuating differences are observed with MLS than with HALOE reflecting the better coverage and geographical matching for MLS. Also, MLS $\mathrm{H}_{2} \mathrm{O}$ data appear almost systematically higher than the balloon observations. As a consequence, the calculated mean absolute differences are the same as the mean difference values except for the $50-65 \mathrm{hPa}$ level for which we obtain $2.91 \pm 1.24 \%(0.13 \pm 0.05 \mathrm{ppmv})$. Overall, the mean absolute differences remain lower for HALOE-ELHYSA than for MLS-ELHYSA reflecting that somewhat better agreement is observed on average between ELHYSA and HALOE.

For the $30-80 \mathrm{hPa}$ range, a systematic positive bias between MLS v3.3 $\mathrm{H}_{2} \mathrm{O}$ and ELHYSA (with respect to the hygrometer) is pointed out between 2004 and 2011. Mean absolute differences (same values for mean differences in the MLS case) reach $2.80 \pm 0.96 \%$ $(0.13 \pm 0.04$ ppmv), namely twice as much as the ELHYSA-HALOE mean absolute differences. An estimation of the bias between the satellite data can be derived from our comparisons using ELHYSA observations as reference. However, associating the MLSELHYSA averaged difference of $2.80 \pm 0.96 \%(0.13 \pm 0.04$ ppmv) with the HALOE-ELHYSA averaged difference of $-0.83 \pm 1.58 \%(-0.04 \pm 0.07 \mathrm{ppmv})$ does not match the $6.60 \pm 2.80 \%$ $(0.27 \pm 0.11 \mathrm{ppmv})$ difference we have found between MLS v3.3 and HALOE v19 from their 2004-2005 overlapping period. Taking into account only the ELHYSA-HALOE comparisons 
for the post-2000 period (2001, 2002 and 2004 cases, excluding our 2005 comparison) turns into a MLS v3.3 - HALOE v19 bias of about 5.30\% (0.24 ppmv) matching the expected value given above.

\section{Discussion and conclusion}

Differences between various water vapour data sets have been widely reported (Kley et al., 2000). Also, corrections have been applied to the NOAA frost-point hygrometer observations obtained over Boulder resulting in newly revised 1980-2000 water vapour trends of up to $40 \%$ lower than previously published (Scherer et al., 2008). These results illustrate the difficulty to derive robust stratospheric water vapour amounts and evolutions from observations as a result of instrumental uncertainties or issues related to comparisons of data with very different spatial resolutions. As particularly recommended by the 2000 SPARC assessment of water vapour (Kley et al., 2000), to evaluate the consistency of the various types of stratospheric water vapour observations, there is a clear need to provide further in situ comparisons of instruments as well as regular validation of satellite data.

In this paper, we have presented intercomparisons between the ELHYSA balloonborne frost-point hygrometer and the HALOE and MLS satellite instruments with a validation purpose. The frost-point hygrometer is firstly described, especially its typical sources of uncertainty. Then, the ELHYSA frost-point is compared with satellite observations on four atmospheric layers. For comparisons as unbiased as possible in terms of age of air issues and stratospheric dynamical effects, only observations conducted in mid-latitude conditions and above the UTLS vertical zone of high variability have been taken into account. This selection process has been conducted using PV coordinates which reduces the direct impact of vortex 
distortion/remnants or of fast transport of younger tropical air towards higher latitudes. It is clear that the used balloon observations are sparse. Notwithstanding the low number of in situ balloon profiles, this work has allowed us to quantify the bias between our balloon frost-point observations and the satellite data. No systematic bias is evident between HALOE and the ELHYSA frost-point especially prior to 2000 . We find a mean difference of $-0.83 \pm 1.58 \%$ (0.04 $\pm 0.07 \mathrm{ppmv}$ ) between HALOE and ELHYSA (with respect to HALOE) in the 30-80 hPa vertical range. We show that the frost-point data are drier by $2.80 \pm 0.96 \%(0.13 \pm 0.04 \mathrm{ppmv})$ on average than MLS v3.3 for 30-80 hPa.

We obtain higher standard deviation values for the ELHYSA-HALOE comparisons which could reflect the flexibility of our time-space coincidence criterion applied to compensate for the sparse HALOE sampling. The relative difference between HALOE and MLS using the ELHYSA data from 1991 to 2011 as reference is smaller than what is expected from published studies of the 2004-2005 HALOE-MLS overlapping period (Lambert et al., 2007). From our 2005 comparison case (ELHYSA flight on 7 October 2005), we have the possibility to compare the frost-point observations with both HALOE and MLS data in the overlapping period. However in this specific case, the expected bias between HALOE and MLS is not apparent certainly as a result of HALOE undersampling issues at the end of its observational period preventing from optimal time-space coincidence with the balloon measurement. Therefore we have investigated monthly-means of HALOE-MLS water vapour taken from their 2004-2005 overlapping period. We find MLS v3.3 $6.60 \pm 2.80 \%$ $(0.27 \pm 0.11 \mathrm{ppmv})$ wetter than HALOE between 30 and $80 \mathrm{hPa}$ which match the balloonsatellite differences given above if we take into account the standard deviation values. To construct a continuous water vapour record from HALOE and MLS data, Solomon et al. (2010) have made the choice to shift HALOE to match MLS based on the unchanging good agreement between the NOAA frost-point record at Boulder and MLS time-series of water 
vapour throughout the period of comparison. Some variability with time is evident between the NOAA frost-point and HALOE (Scherer et al., 2008). The question is whether or not the HALOE water vapour signal is affected by a time-dependent drift in instrument response or calibration to explain these varying differences with the NOAA frost-point and with MLS. Randel et al. (2006) mentions that there is no effect of HALOE instrumental drift throughout 13 years of observations. We note that differences between the ELHYSA frost-point and HALOE appear also variable with time, with higher differences after 2000 (excluding our 2005 ELHYSA-HALOE coincidence which is subject to caution). Taking into account ELHYSA-HALOE comparisons only for the post-2000 period results in HALOE-MLS differences in agreement with the expected value which might be indication of a drift of HALOE. The somewhat unchanged differences between ELHYSA and MLS reflect a steady systematic bias between both instruments rather than any clear effect of instrumental drifts.

Of course, there would be a need for more ELHYSA-satellite comparisons to derive definitive conclusions about the stability of the satellite records of water vapour and about the choice to adjust HALOE on MLS as a systematic approach. A valuable future strategy would be to simultaneously compare the ELHYSA and ELHYSA2 (successor of ELHYSA currently under development) instruments to the observations by the PicoSDLA- $\mathrm{H}_{2} \mathrm{O}$ infrared spectrometer, the Fluorescent Advanced Stratospheric Hygrometer for Balloon (FLASH-B) Lyman-alpha hygrometer (Yushkov et al., 2001) and the CFH frost point (Vömel et al., 2007a). Data quality questions for such in situ instruments using a variety of techniques is still to be addressed for robust estimations of possible satellite data biases which will be in turn a consistent basis to establish long-term water vapour trends and deal with problems of merging satellite data sets in the future. Note that in any case, water vapour trends estimated from a specific long-term data set would be considered as consistent if offset differences (bias) with other instruments remain stable throughout their operational period. 
Acknowledgements. The authors are very grateful to Joëlle and Henri Ovarlez, now retired but definitively associated to this work, for the development of the ELHYSA hygrometer (or formerly LMD hygrometer in the literature), for their involvement in the numerous successful balloon/aircraft flights, for their strong support and nice advices in the frame of this study. The balloon flights were funded by CNES, by the European Space Agency (ESA) in the frame of ENVISAT satellite validation, by the French national research programs (now LEFE-CHAT and formerly PNCA) and by the European Commission for extensive international balloon campaigns. The authors would like in particular to thank the newlycreated French CNES-INSU Balloon Committee (so-called CSTB) for funding of the AEROWAVE (Aerosols, Water Vapour and Electricity) project (2010 and 2011 campaigns). We wish to make special thanks to the CNES balloon launching and operational teams who launched successfully so many times the ELHYSA instrument over the past 20 years. ELHYSA data can be found on the ETHER database (http://ether.ipsl.jussieu.fr) supported by CNES and CNRS-INSU and managed by Institut Pierre Simon Laplace (IPSL). Thanks also go to Jeremy Surcin and Matthieu Jeannot (LPC2E) for precious support on the extraction of satellite data and on various computing issues. Alain Hauchecorne and Marc-Antoine Drouin are acknowledged for support on the MIMOSA model which is important part of this work. We thank Gérard Coeur-Joly and Daniel Sourgen from LMD/Palaiseau for their support on the laboratory calibration system of the frost-point hygrometer. The authors are also grateful to Peter Haynes for very useful discussions about stratospheric transport and water vapour issues in Cambridge, UK. Finally, our deep thoughts are with Cornelius Schiller who was one of the most active scientists in the world to consider the question of water vapour in particular through the SPARC Water Vapour Initiative. 


\section{References}

Berthet, G, Renard, J.-B., Catoire, V., Chartier, M., Robert, C., Huret, N., Coquelet, F., Bourgeois, Q.: Remote sensing measurements in the polar vortex: comparison to in situ observations and implications for the simultaneous retrievals and analysis of the $\mathrm{NO}_{2}$ and OClO species. J. Geophys. Res. 112(D21310), (2007a). doi:10.1029/2007JD008699

Berthet, G., Esler, J.G., Haynes, P.H.: A lagrangian perspective of the tropopause and the ventilation of the lowermost stratosphere. J. Geophys. Res. 112(D18102), (2007b). doi:10.1029/2006JD008295

Bonazzola, M., Haynes, P.H.: A trajectory-based study of the tropical tropopause region. J. Geophys. Res. 109(D20112), (2004). doi:10.1029/2003JD004356

Brewer, A.W.: Evidence for a world circulation provided by measurements of helium and water vapor distribution in the stratosphere. Quart. J. Roy. Meteor. Soc. 75, 351-363 (1949)

Considine, D.B., Rosenfield, J.E., Fleming, E.L.: An interactive model study of the influence of the mount Pinatubo aerosol on stratospheric methane and water trends. J. Geophys. Res. 106, 27711-27727 (2001)

Dethof, A., O’Neill, A., Slingo J.M., Smit, H.G.J.: A mechanism for moistening the lower stratosphere involving the Asian summer monsoon. Quart. J. Roy. Meteor. Soc. 125, 1079$1106(1999)$

Durry, G., Hauchecorne, A., Ovarlez, J., Ovarlez, H., Pouchet, I., Zeninari, V., Parvitte, B.: In situ measurements of $\mathrm{H}_{2} \mathrm{O}$ and $\mathrm{CH}_{4}$ with telecommunication laser diodes in the lower stratosphere: dehydration and indication of a tropical air intrusion at mid-latitude. J. Atmosph. Chem. 43, 175-194 (2002) 
Durry, G., Amarouche, N., Joly, L., Liu, X., Zéninari, V. and Parvitte, B.: Laser diode spectroscopy of $\mathrm{H}_{2} \mathrm{O}$ at 2.63 micron for atmospheric applications, Applied Physics B 90, $573-580(2008)$

Dvortsov, V.L., Solomon S.: Response of the stratospheric temperatures and ozone to past and future increases in stratospheric humidity. J. Geophys. Res. 106(D7), 7505-7514 $(2001)$

Forster, P.M. de F., Shine, K.P.: Stratospheric water vapor changes as a possible contributor to observed stratospheric cooling. Geophys. Res. Lett. 26, 3309-3312 (1999)

Forster, P.M. de F., Shine, K.P.: Assessing the climate impact of trends in stratospheric water vapor. Geophys. Res. Lett. 29(6), 1086 (2002). doi:10.1029/2001GL013909

Fueglistaler, S., Haynes, P.H.: Control of interannual and longer-term variability of stratospheric water vapor. J. Geophys. Res. 110(D24108), (2005). doi:10.1029/2005JD006019

Goff, J. A., and S. Gratch, Low-pressure properties of water from -160 to 212 F. Trans. Am. Soc. Heating Ventilating Eng. 52, 95-122 (1946)

Harries, J.E., Russell III, J.M., Tuck, A.F., Gordley, L.L., Purcell, P., Stone, K., Bevilacqua, R., Gunson, M.R., Nedoluha, G., Traub W.A.: Validation of Measurements of Water Vapor from the Halogen Occultation Experiment, HALOE. J. Geophys. Res. 101(D6), $10205-10216(1996)$

Hauchecorne, A., Godin, S., Marchand, M., Heese, B., Souprayen, C.: Quantification of the transport of chemical constituants from the polar vortex to middle latitudes in the lower stratosphere using the high-resolution advection model MIMOSA and effective diffusivity. J. Geophys. Res. 107(D20), 8289 (2002). doi:10.1029/2001JB000491 
Hervig, M., Russell, J.M., Gordlen, L. L., Daniels, T., Drayson, S.R., Park, J.H.: Aerosol effects and corrections in the Halogen Occultation Experiment. J. Geophys. Res. 100, 1067-1079 (1995)

Holton, J.R., Haynes, P.H., McIntyre, M., Douglass, A., Rood, R., Pfister, L.: Stratospheretroposphere exchange. Rev. Geophys. 33, 403-439 (1995)

Hurst, D.F., Oltmans, S.J., Vömel, H., Rosenlof, K.H., Davis, S.M., Ray, E.A., Hall, E.G., Jordan, A.F.: Stratospheric water vapor trends over Boulder, Colorado: Analysis of the 30 year Boulder record. J. Geophys. Res. 116(D02306), (2011). doi:10.1029/2010JD015065

Jensen, E., Toon, O., Vay, S., Ovarlez, J., May, R., Bui, P., Twohy, C.H., Grandud, B., Pueschel, R., Schumann, U.: Prevalence of ice supersaturated regions in the upper troposphere : implication for Optically thin ice cloud formation. J. Geophys. Res. 106(D3), $17253-17266(2001)$

Joshi, M.M., Shine, K.P.: A GCM study of volcanic eruptions as a cause of increased stratospheric water vapor, J. of Climate 16, 3525-3534 (2003)

Junge, C.E., Chagnon, C.W., Manson J.E.: A world-wide stratospheric aerosol layer, Science 133, 1478-1479 (1961)

Kanzawa, H., Schiller, C., Ovarlez, J., et al.: Validation and data characteristics of water vapor profiles observed by the Improved Limb Atmospheric Spectrometer (ILAS) and processed with Version 5.20 algorithm. J. Geophys. Res. 107(D24), 8217 (2002). doi:10.1029/2001JD000881

Kirk-Davidoff, D.B., Hinsta, E.J., Anderson, J.G., Keith D.W.: The effect of climate change on ozone depletion through change in stratospheric water vapor. Nature 402, 399-401 (1999) 
Kley, D., Russell III, J.M., Phillips, C.: SPARC Assessment of upper tropospheric and stratospheric water vapor. WCRP-113, WMO/TD-No. 1043, World Meteorol. Org., Geneva (2000)

Lambert, A., et al.: Validation of the Aura Microwave Limb Sounder stratospheric water vapor and nitrous oxide measurements. J. Geophys. Res. 112(D24S36), (2007). doi:10.1029/2007JD008724

le Texier, H., Solomon, S., Garcia, R. R.: The role of molecular hydrogen and methane oxidation in the water vapor budget of the stratosphere. Q. J. R. Meteorol. Soc. 114, 281295 (1988). doi:10.1002/qj.49711448002

Liang, C.K., Eldering, A., Gettelman, A., Tian, B., Wong, S., Fetzer, E.J., and Liou K.N.: Record of tropical interannual variability of temperature and water vapor from a combined AIRS-MLS data set. J. Geophys. Res. 116(D06103), (2011). doi: 10.1029/2010JD014841

Livesey, N.J., Snyder, W.V., Read, W.G., Wagner, P. A.: Retrieval algorithms for the EOS Microwave Limb Sounder (MLS). IEEE Trans. Geosci. Remote Sens. 44, 1144- 1155 (2006)

Livesey, N. J.: EOS MLS Version 3.3 level 2 data quality and description document, technical report, Jet Propul. Lab., Pasadena, Calif. (2011)

Michelsen, H. A., et al.: ATMOS version 3 water vapor measurements: Comparisons with observations from two ER-2 Lyman- $\alpha$ hygrometers, MkIV, HALOE, SAGE II, MAS, and MLS. J. Geophys. Res. 107(D3), 4027 (2002). 10.1029/2001JD000587

Montoux, N., Hauchecorne, A., Pommereau, J.-P., Lefèvre, F., Durry, G., Jones, R.L., Rozanov, A., Dhomse, S., Burrows, J.P., Morel, B., Bencherif, H.: Evaluation of balloon and satellite water vapour measurements in the Southern tropical and subtropical UTLS during the HIBISCUS campaign. Atmos. Chem. Phys. 9, 5299-5319 (2009) 
Mote, P.W., Rosenlof, K.H., Holton, J.R., Harwood, R.S., Waters, J.W.: An atmospheric tape recorder: The imprint of tropical tropopause temperatures on stratospheric water vapor. J. Geophys. Res. 101, 3989-4006 (1996)

Notholt, J., Luo, B. P., Fueglistaler, S., Weisenstein, D., Rex, M., Lawrence, M.G., Bingemer, H., Wohltmann, I., Corti, T., Warneke, T., von Kuhlmann, R., Peter, T.: Influence of tropospheric $\mathrm{SO}_{2}$ emissions on particle formation and the stratospheric humidity. Geophys. Res. Lett. 32(L07), 810 (2005). doi:10.1029/2004GL022159

Oltmans, S. J., Hofmann, D. J.: Increase in lower-stratospheric water vapor at a Mid-latitude Northern Hemisphere site from 1981 to 1994 . Nature 374, 146-149 (1995)

Oltmans, S.J., Vömel, H., Hofmann, D., Rosenlof, K., Kley, D.: The increase in stratospheric water vapor from balloon-borne, frost point hygrometer measurements at Washington, D.C. and Boulder, Colorado. Geophys. Res. Lett. 27(21), 3453-3456 (2000)

Orsolini, Y.J., Manney, G.L., Engel, A., Ovarlez, J., Claud, C., Coy, L.: Layering in stratospheric profiles of long lived trace species: Balloon-borne observations and modelling. J. Geophys. Res. 103(D5), 5815-5825 (1998)

Ovarlez, J.: Stratospheric Water Vapor Measurement in the tropical Zone by means of a Frost-point Hygrometer on Board Long-Duration Balloons. J. Geophys. Res. 96(D8), $15541-15554(1991)$

Ovarlez, J., van Velthoven, P., Sachse, G., Vay, S., Schlager, H., Ovarlez, H.: Comparison of water vapor measurements from POLINAT 2 with ECMWF analyses in high humidity conditions. J. Geophys. Res. 105(D3), 3737-3744 (2000)

Ovarlez, J., Gayet, J.-F., Gierens, K., Ström, J., Ovarlez., H., Auriol, F., Busen, R., Schumann, U.: Water vapor measurements inside cirrus clouds in Northern and Southern Hemispheres during INCA. Geophys. Res. Lett. 29(16), (2002). 10.1029/2001GL014440 
Plumb, R.A.: A “tropical pipe” model of stratospheric transport. J. Geophys. Res. 101, 957$3972(1996)$

Pruvost, P., Ovarlez, J., Lenoble, J., Chu, W.P.: Comparison of Stratospheric Aerosol and Gas Experiment and Balloon-Borne Stratospheric Water Vapor Measurement. J. Geophys. Res. 98(D3), 4889-4896 (1993)

Randel, W.J., Wu, F., Gettelman, A., Russell III, J.M., Zawodny, J.M., Oltmans, S.J.: Seasonal variation of water vapor in the lower stratosphere observed in Halogen Occultation Experiment data. J. Geophys. Res. 106, 14313-14325 (2001)

Randel, W.J., Wu, F., Oltmans, S.J., Rosenlof, K., Nedoluha, G.E.: Interannual changes of stratospheric water vapor and correlations with tropical tropopause temperature. J. Atmos. Sci. 61(17), 2133-2148 (2004). doi:10.1175/1520-0469(2004)061

Randel, W.J., Wu, F., Vömel, H., Nedoluha, G.E., Forster, P.: Decreases in stratospheric water vapor after 2001: Links to changes in the tropical tropopause and the BrewerDobson circulation. J. Geophys. Res. 111(D12312), (2006). doi:10.1029/2005JD006744

Read, W. G., et al.: Aura Microwave Limb Sounder upper tropospheric and lower stratospheric $\mathrm{H}_{2} \mathrm{O}$ and RHi validation. J. Geophys. Res. 112(D24S35), (2007). doi:10.1029/2007JD008752

Renard, J.-B., Brogniez, C., Berthet, G., Bourgeois, Q., Gaubicher, B., Chartier, M., Auriol, F., Balois, J.-Y., François, P., Verwaerde, C., Daugeron, D.: Vertical distribution of the different types of aerosols in the stratosphere: Detection of solid particles and analysis of their spatial variability. J. Geophys. Res. 113(D21303), (2008). doi:10.1029/2008JD010150

Rind, D., Chiou., E.W, Chu, W., et al.: Positive water vapor feedback in climate models confirmed by satellite data. Nature 349(6309), 500-503 (1991) 
Rohs, S., Schiller, C., Riese, M., Engel, A., Schmidt, U., Wetter, T., Levin, I., Nakazawa, T., Aoki, S.: Long-term changes of methane and hydrogen in the stratosphere in the period 1978-2003 and their impact on the abundance of stratospheric water vapor. J. Geophys. Res. 111(D14315), (2006). doi:10.1029/2005JD006877

Rosenlof, K., Oltmans, S., Kley, D., Russell III, J.M., et al.: Stratospheric water vapor increases over the past half-century, Geophys. Res. Lett. 28(7), 1195-1198 (2001)

Russell III, J.M., Gordley, L.L., Park, J.H., Drayson, S.R., Hesketh, W.D., Cicerone, R.J., Tuck, A.F., Frederick, J.E., Harries, J.E., Crutzen, P.J.: The Halogen Occultation Experiment. J. Geophys. Res. 98, 10777-10798 (1993)

Russell, P.B., Livingston, J.M., Pueschel, R.F., Bauman, J.J., Pollack, J.B., Brooks, S.L., Hamill, P., Thomason, L.W., Stowe, L.L., Deshler, T., Dutton, E.G., Bergstrom, R.W.: Global to microscale evolution of the Pinatubo volcanic aerosol derived from diverse measurements and analyses. J. Geophys. Res. 101, 18745-18763 (1996)

Scaife, A.A., Butchard, N., Jackson, D.R., Swinbank, R., Can changes in ENSO activity help to explain increasing stratospheric water vapor? Geophys. Res. Lett. 30(17), 1880 (2003). doi:10.1029/2003GL017591

Scherer, M., Vömel, H., Fueglistater, S., Oltmans, S.J., Staehelin, J.: Trends and variability of mid-latitude stratospheric water vapour deduced from the re-evaluated balloon series and HALOE. Atmos. Chem. Phys. 8, 1391-1402 (2007)

Schiller, C., et al.: Dehydration in the Arctic stratosphere during the SOLVE/THESEO-2000 campaigns. J. Geophys. Res. 107, 8293 (2002). doi:10.1029/2001JD000463

Seidel, D.J., Ross, R.J., Angell, J.K., Reid, G.C.: Climatological characteristics of the tropical tropopause as revealed by radiosondes. J. Geophys. Res. 106, 7857-7878 (2001). doi:10.1029/2000JD900837 
Sherwood, S.: A Microphysical Connection Among Biomass Burning, Cumulus Clouds, and Stratospheric Moisture. Science 295, 1272-1275 (2002)

Shindell, D.T.: Climate and ozone response to increased stratospheric water vapor. Geophys. Res. Lett. 28, 1551-1554 (2001)

Solomon, S., Rosenlof, K.H., Portmann, R.W., Daniel, J.S., Davis, S.M., Sanford, T.J., Plattner G.-K.: Contribution of stratospheric water vapor to decadal changes in the rate of global warming. Science 327, 1219-1223 (2010)

Sugita, T., et al.: Ozone profiles in the high-latitude stratosphere and lower mesosphere measured by the Improved Limb Atmospheric Spectrometer (ILAS)-II: Comparison with other satellite sensors and ozonesondes. J. Geophys. Res. 111(D11S02), (2006). doi:10.1029/2005JD006439

Swartz, W.H., Yee, J.-H., Randall, C.E., Shetter, R.E., Browell, E.V., Burris, J.F., McGee, T.J., Avery, M.A.: Comparison of high-latitude line of sight ozone column density with derived ozone fields and the effects of horizontal inhomogeneity. Atmos. Chem. Phys. 6, $1843-1852(2006)$

Teitelbaum, H., Ovarlez, J., Kelder, H., Lott, F.: Some observations of gravity-wave-induced structure in ozone and water vapor during EASOE. Geophys. Res. Lett. 21(13), 1483-1486 (1994)

Voigt, C., Schreiner, J., Mausberger, K., Ovarlez, J., Ovarlez, H., David, C., Dornbrack, A.: Nitric Acid Trihydrate in Polar Stratospheric Cloud Particles. Science 290, 1756-1758 (2000)

Vömel, H., David, D.E., Smith, K.: Accuracy of tropospheric and stratospheric water vapor measurements by the cryogenic frost point hygrometer: Instrumental details and observations. J. Geophys. Res. 112(D08305), (2007a). doi:10.1029/2006JD007224 
Vömel, H., et al.: Validation of Aura/MLS water vapor by balloon-borne cryogenic frostpoint hygrometer measurements. J. Geophys. Res. 112(D24S37), (2007b). doi:10.1029/2007JD008698

Vömel, H., Yushkov, V., Khaykin, S., Korshunov, L., Kyrö, E., Kivi, R.: Intercomparisons of stratospheric water vapor sensors: FLASH-B and NOAA/CMDL Frost-Point hygrometer. J. Atmos. Oc. Tech. 24, 941-952 (2007c)

Waters, J.W., et al.: The Earth Observing System Microwave Limb Sounder (EOS MLS) on the Aura satellite, Experiment. IEEE Trans. Geosci. Remote Sens. 44(5), 1075-1092 (2006). doi:10.1109/TGRS.2006.873771

Yushkov, V., Sitnikov, N., Zaitcev, I., Pommereau, J.-P., Garnier, A.: Stratospheric water vapor measurements in the winter Arctic with optical fluorescence hygrometer on short and long duration balloons. Proc. $15^{\text {th }}$ ESA Symp. on European Rocket and Balloon Programmes and Related Research, Biarritz, France, ESA, 263-268 (2001)

Zhou, X.-L., Geller, M.A., Zhang, M.: Cooling trend of the tropical cold point tropopause temperatures and its implications. J. Geophys. Res. 106, 1511-1522 (2001). doi:10.1029/2000JD90047 
Table 1: Flight list of the ELHYSA frost point hygrometer from two balloon launching sites for comparisons with HALOE and MLS in mid-latitude conditions.

Table 1 Flight list of the ELHYSA frost point hygrometer from two balloon launching sites for comparisons with HALOE and MLS in mid-latitude conditions

\begin{tabular}{|c|c|c|c|}
\hline Date & Project or Campaign & Launching site & Dynamical conditions \\
\hline 20 Nov $1991^{a}$ & EASOE & Kiruna/Esrange & Mainly outer vortex ${ }^{\mathrm{c}}$ \\
\hline 07 Mar $1993^{\mathrm{a}}$ & TRAVERSE & Aire sur l'Adour & Midlatitudes \\
\hline 10 Aug $1998^{\mathrm{a}}$ & SABINE & Kiruna/Esrange & Summertime high latitudes \\
\hline 05 May $1999^{a}$ & THESEO & Aire sur l'Adour & Midlatitudes, presence of tropical air ${ }^{\mathrm{d}}$ \\
\hline 22 Oct $2001^{\mathrm{a}}$ & ODIN validation & Aire sur l'Adour & Midlatitudes, presence of tropical air ${ }^{\mathrm{d}}$ \\
\hline $06 \operatorname{Dec} 2002^{\mathrm{a}}$ & CIPA & Kiruna/Esrange & Outer vortex below $65 \mathrm{hPa}$ \\
\hline 11 Mar $2004^{a}$ & ENVISAT validation & Kiruna/Esrange & Outer vortex \\
\hline 07 Oct $2005^{\mathrm{ab}}$ & French National Program & Aire sur l'Adour & Midlatitudes \\
\hline 26 Aug $2009^{b}$ & French National Program & Kiruna/Esrange & Summertime high latitudes \\
\hline 04 Apr $2010^{\mathrm{b}}$ & French National Program & Kiruna/Esrange & Outer vortex below $40 \mathrm{hPa}^{\mathrm{c}}$ \\
\hline 09 Apr $2010^{\mathrm{b}}$ & French National Program & Kiruna/Esrange & Outer vortex below $45 \mathrm{hPa}^{\mathrm{c}}$ \\
\hline 12 Mar $2011^{\mathrm{b}}$ & French National Program & Kiruna/Esrange & Mainly outer vortex below $65 \mathrm{hPa}^{\mathrm{c}}$ \\
\hline
\end{tabular}

${ }^{a}$ Observations used for comparisons with HALOE for extra-vortex conditions

${ }^{\mathrm{b}}$ Observations used for comparisons with MLS

${ }^{\mathrm{c}}$ Presence of extra vortex air but some vertical levels with inner vortex air or mixed air need to be excluded

${ }^{\mathrm{d}}$ Vertical levels characterized by tropical intrusions need to be excluded 
Table 2: Mean differences and mean absolute differences (at the 1- $\sigma$ level) between v3.3 MLS and v19 HALOE datasets and the observations by the ELHYSA balloon-borne frost point hygrometer for various vertical levels. Values are for the 1991-2005 and 2004-2011 periods for HALOE and MLS respectively. Percentage values are given with respect to frost point observations.

\begin{tabular}{|c|c|c|c|c|c|}
\hline Compared data sets & $\frac{30-40 \mathrm{hPa}}{(18-19 \mathrm{~km})}$ & $\frac{40-50 \mathrm{hPa}}{(19-20 \mathrm{~km})}$ & $\frac{50-65 \mathrm{hPa}}{(20-22 \mathrm{~km})}$ & $\frac{65-80 \mathrm{hPa}}{(22-24 \mathrm{~km})}$ & $\frac{30-80 \mathrm{hPa}}{(18-24 \mathrm{~km})}$ \\
\hline $\begin{array}{l}\frac{\text { HALOE v19 - Frost }}{\text { point }} \\
\text { Mean difference } \\
\text { Mean absolute difference }\end{array}$ & $\begin{array}{l}\frac{0.08 \pm 2.39 \%}{0.00 \pm 0.11 \mathrm{ppmv}} \\
\underline{2.00 \pm 1.02 \%} \\
\underline{0.10 \pm 0.04 \mathrm{ppmv}}\end{array}$ & $\begin{array}{c}\frac{-0.07 \pm 0.93 \%}{\underline{0.00 \pm 0.04 \mathrm{ppmv}}} \\
\underline{0.82 \pm 0.24 \%} \\
\underline{0.04 \pm 0.01 \mathrm{ppmv}}\end{array}$ & $\begin{array}{c}\frac{-0.04 \pm 0.11 \mathrm{ppmv}}{\frac{-0.04 .49 \%}{2.01 \pm 1.54 \%}} \\
\underline{0.09 \pm 0.07 \mathrm{ppmv}}\end{array}$ & $\begin{array}{c}\frac{-1.62 \pm 2.58 \%}{-0.07 \pm 0.11 \mathrm{ppmv}} \\
\underline{2.52 \pm 1.53 \%} \\
\underline{0.10 \pm 0.06 \mathrm{ppmv}}\end{array}$ & $\begin{array}{c}\frac{-0.83 \pm 1.58 \%}{-0.04 \pm 0.07 \mathrm{ppmv}} \\
\underline{1.48 \pm 0.90 \%} \\
\underline{0.07 \pm 0.04 \mathrm{ppmv}}\end{array}$ \\
\hline MLS v3.3 - Frost point & & & & & \\
\hline $\begin{array}{c}\text { Mean difference } \\
\text { Mean absolute difference }\end{array}$ & $\begin{array}{l}\frac{3.32 \pm 1.17 \%}{0.16 \pm 0.05 \mathrm{ppmv}} \\
\underline{0.16 \pm 0.05 \mathrm{ppmv}}\end{array}$ & $\begin{array}{l}\frac{2.75 \pm 0.54 \%}{0.13 \pm 0.02 \mathrm{ppmv}} \\
\frac{2.75 \pm 0.54 \%}{0.13 \pm 0.02 \mathrm{ppmv}}\end{array}$ & $\begin{array}{l}\frac{2.28 \pm 2.43 \%}{0.10 \pm 0.11 \mathrm{ppmv}} \\
\underline{0.13 \pm 0.05 \mathrm{ppmv}}\end{array}$ & $\begin{array}{l}\frac{2.69 \pm 1.04 \%}{0.12 \pm 0.05 \mathrm{ppmv}} \\
\frac{2.69 \pm 1.04 \%}{0.12 \pm 0.05 \mathrm{ppmv}}\end{array}$ & $\begin{array}{l}\frac{2.80 \pm 0.96 \%}{0.13 \pm 0.04 \mathrm{ppmv}} \\
\frac{2.80 \pm 0.96 \%}{0.13 \pm 0.04 \mathrm{ppmv}}\end{array}$ \\
\hline
\end{tabular}



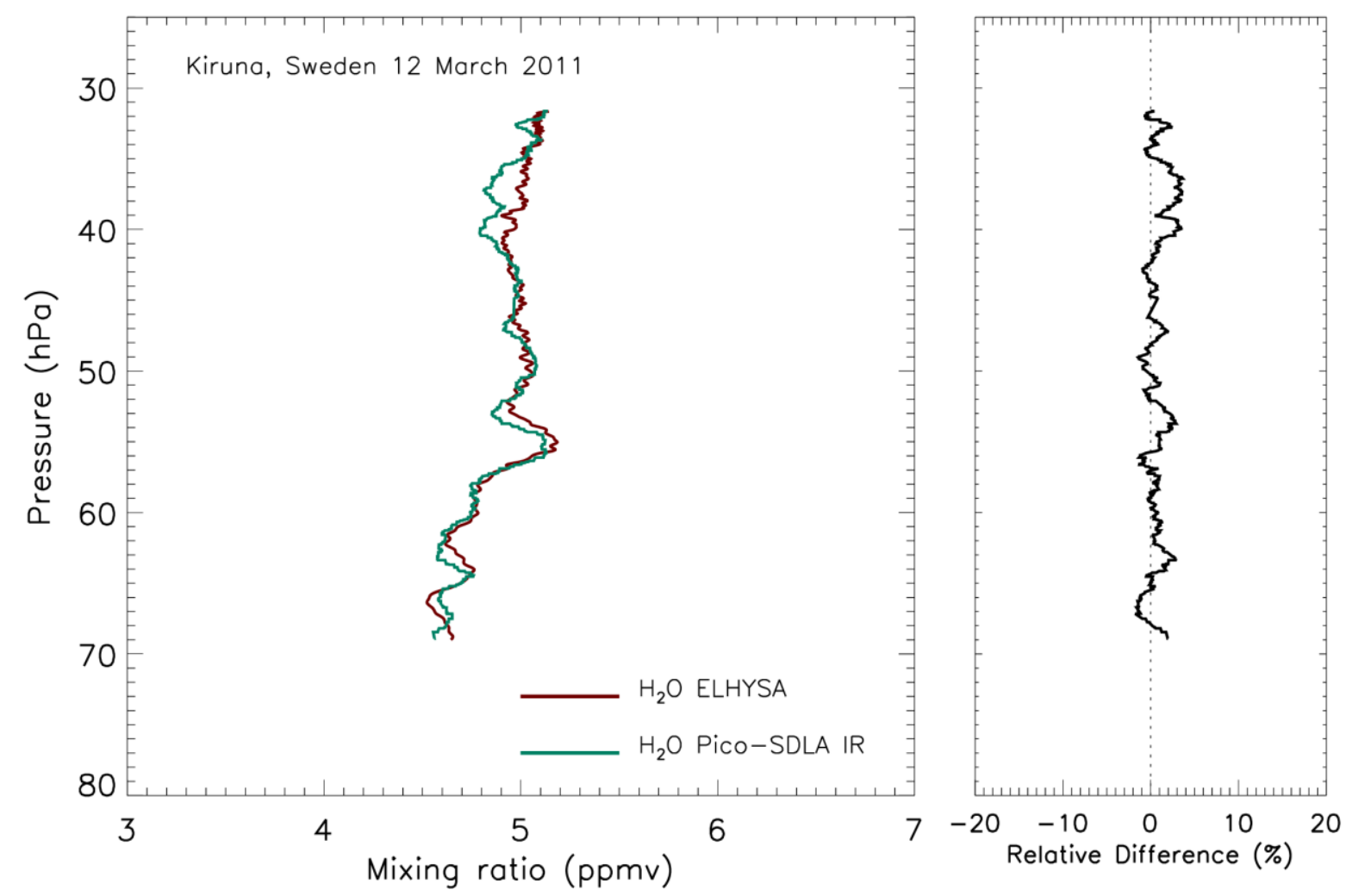

Figure 1: Simultaneous in situ observations of stratospheric water vapour obtained by the ELHYSA frost-point hygrometer and the PicoSDLA infrared spectrometer on 12 March 2011 from Kiruna/Esrange (Northern Sweden, $67.9^{\circ} \mathrm{N}, 21.1^{\circ} \mathrm{E}$ ) during the balloon descent. The percentage difference between the two instruments with respect to ELHYSA data is also presented. 

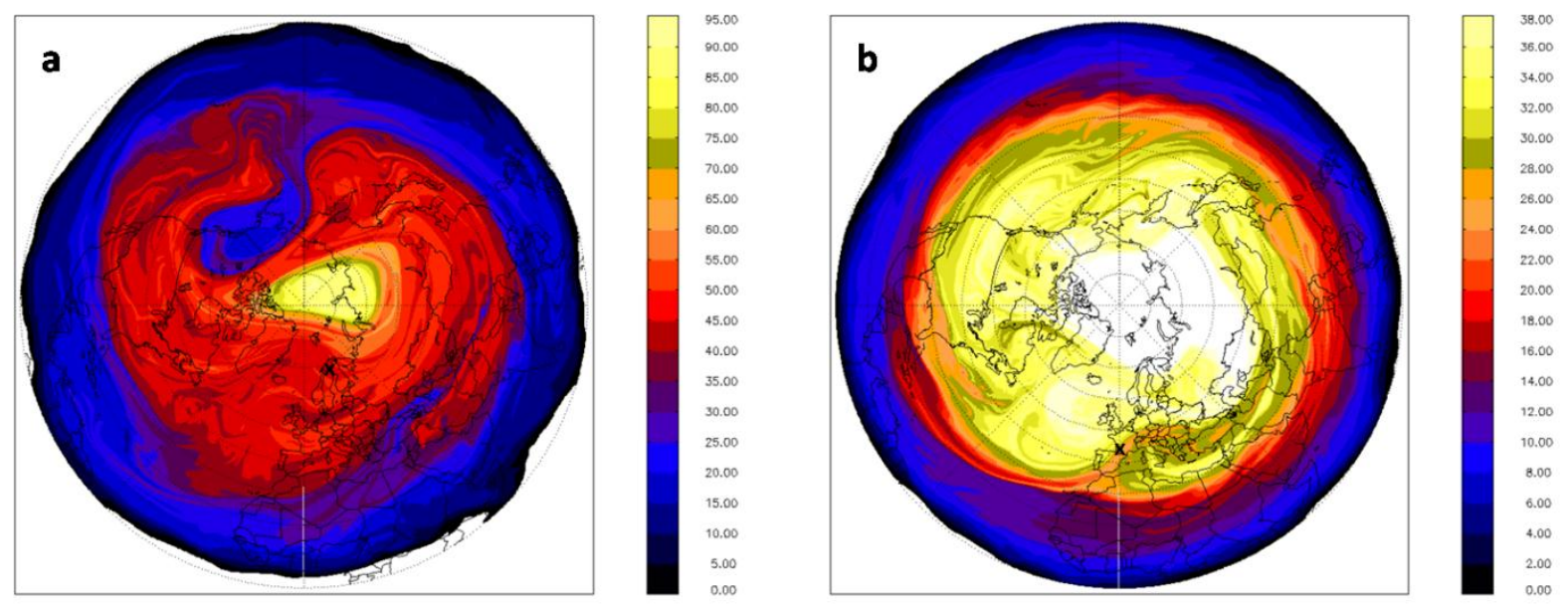

Figure 2: Example of PV fields computed by the MIMOSA model and used to exclude vortex air signatures (a) and tropical intrusions (b) in the ELHYSA frost point profiles and in the mid-latitude satellite data. For the flight from Kiruna/Esrange (Northern Sweden, $67.9^{\circ} \mathrm{N}$, $\left.21.1^{\circ} \mathrm{E}\right)$ at the $540 \mathrm{~K}$ isentropic level $(34 \mathrm{hPa}, \sim 22.5 \mathrm{~km})$ on 11 March 2004, mid-latitude conditions are reached for typical PV values in the range 40-50 pvu and the vortex air is flagged with PV > 50 pvu (a); for the flight from Aire sur l'Adour (Southern France, $43.7^{\circ} \mathrm{N}$, $\left.0.3^{\circ} \mathrm{W}\right)$ at the $510 \mathrm{~K}$ isentropic level $(47.5 \mathrm{hPa}, \sim 21 \mathrm{~km})$ on 22 October 2001, mid-latitude conditions are considered for PV > 30 pvu and tropical air influence is highlighted for PV < 30 pvu (b). Both balloon launch locations are represented by a black cross. Contour units are $\left(10^{-8} \mathrm{~K} \mathrm{~m}^{2} \mathrm{~s}^{-1} \mathrm{~kg}^{-1}\right)$. 


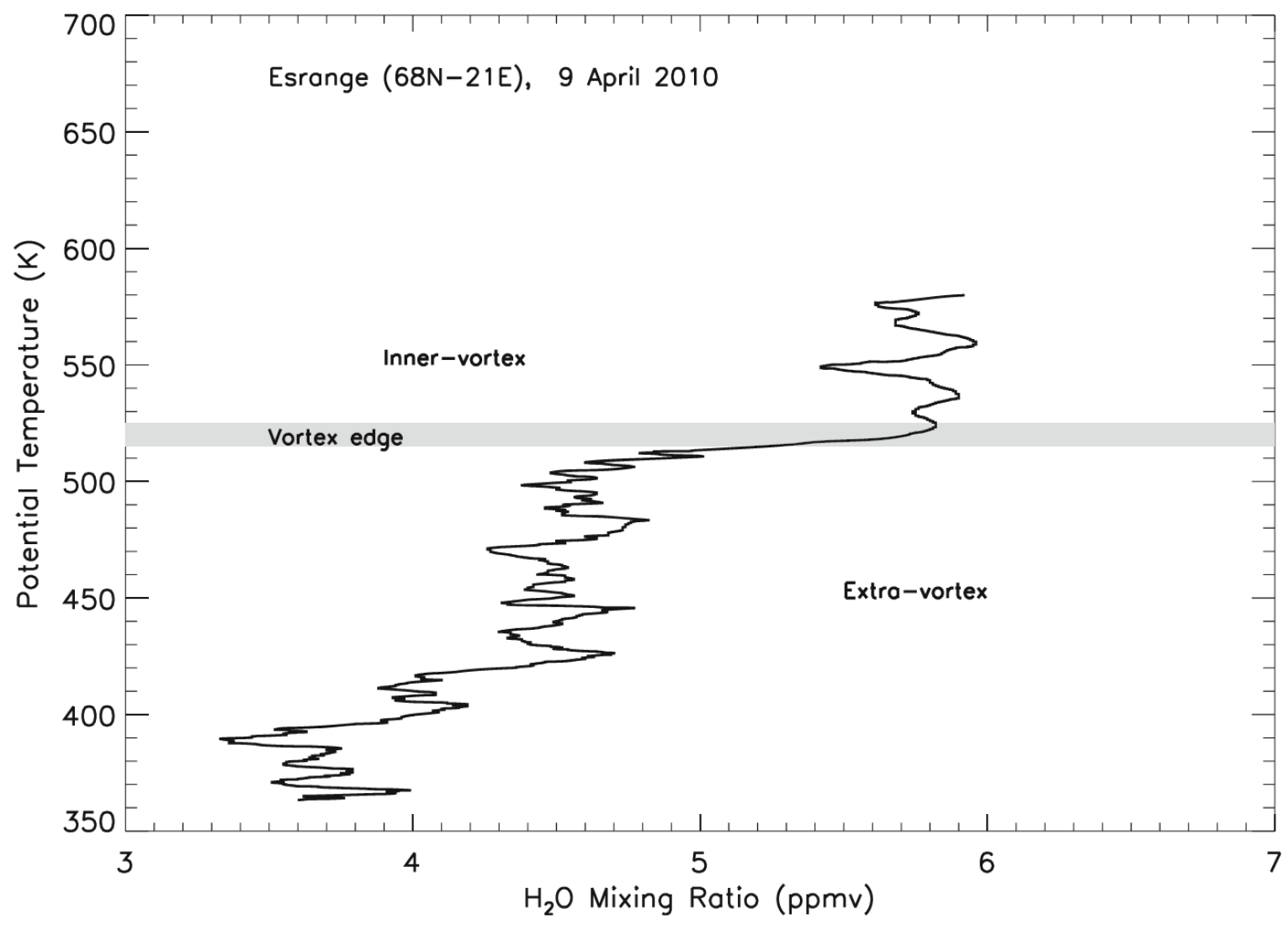

Figure 3: High-resolution vertical profile of water vapour observed at high-latitude by the ELHYSA hygrometer illustrating the impact of the position of the vortex barrier (shaded grey) on the stratospheric water vapour amounts. 


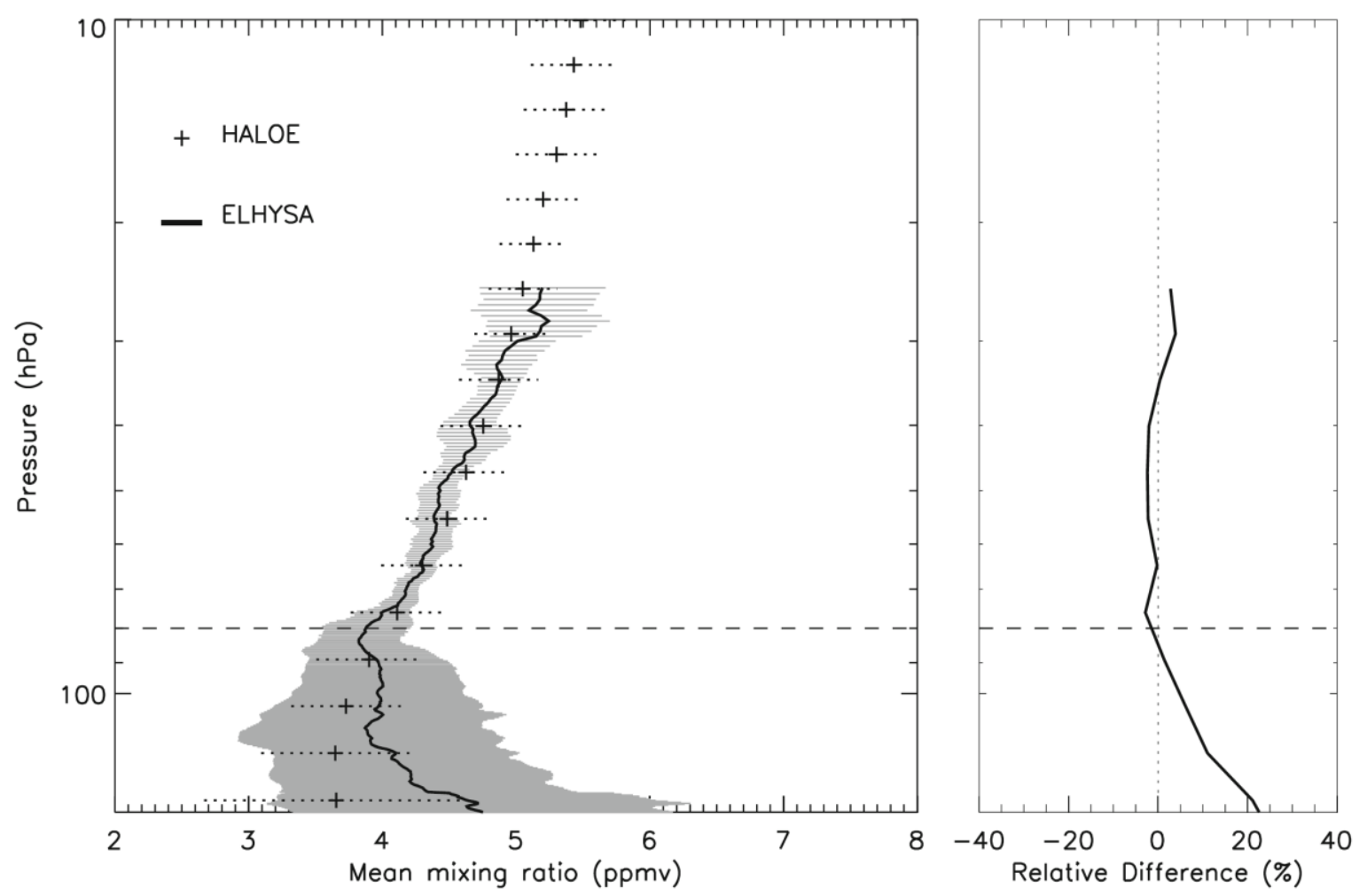

Figure 4: Averaged ELHYSA (thick line) and HALOE (plus signs) vertical profiles of water vapour for the seven ELHYSA flights between 1991 and 2005. The selected ELHYSA profiles (Table 1) have been interpolated between 11 and $150 \mathrm{hPa}$ onto a fixed grid and averaged. HALOE data have been averaged within each $1 \mathrm{~km}$ altitude bin of a fixed vertical grid. Error bars represent the 1-sigma standard deviations. 

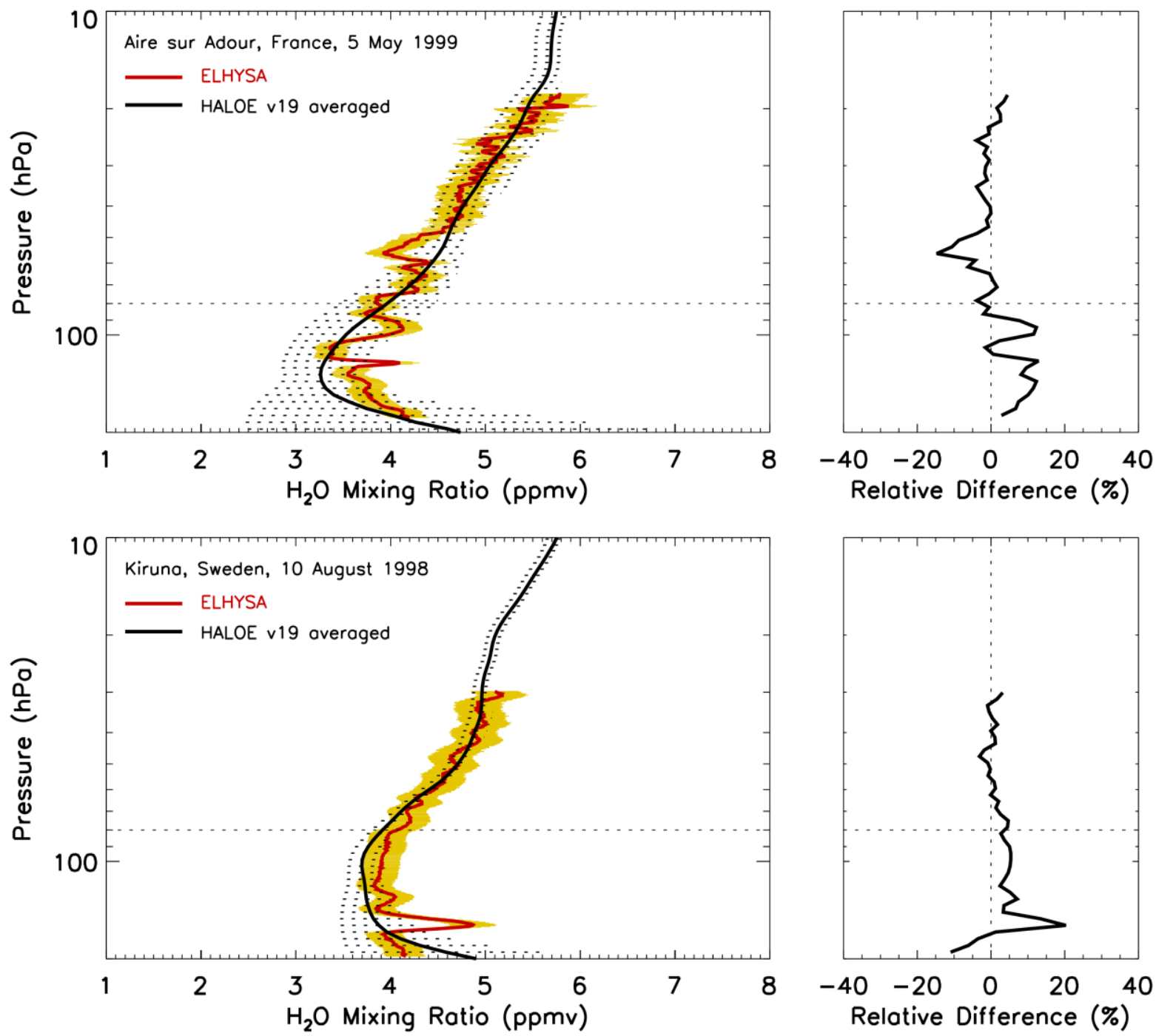

Figure 5: Vertical profiles of water vapour observed by the ELHYSA frost point hygrometer on 5 May 1999 at the Aire sur l'Adour mid-latitude site (top) and on 10 August 1998 at the Kiruna high-latitude site (bottom) and compared to HALOE observations. The balloon profiles have been interpolated onto a fixed grid and averaged. Mid-latitude HALOE data have been averaged within each altitude bin of the fixed vertical grid. Error bars represent the 1-sigma standard deviations. 

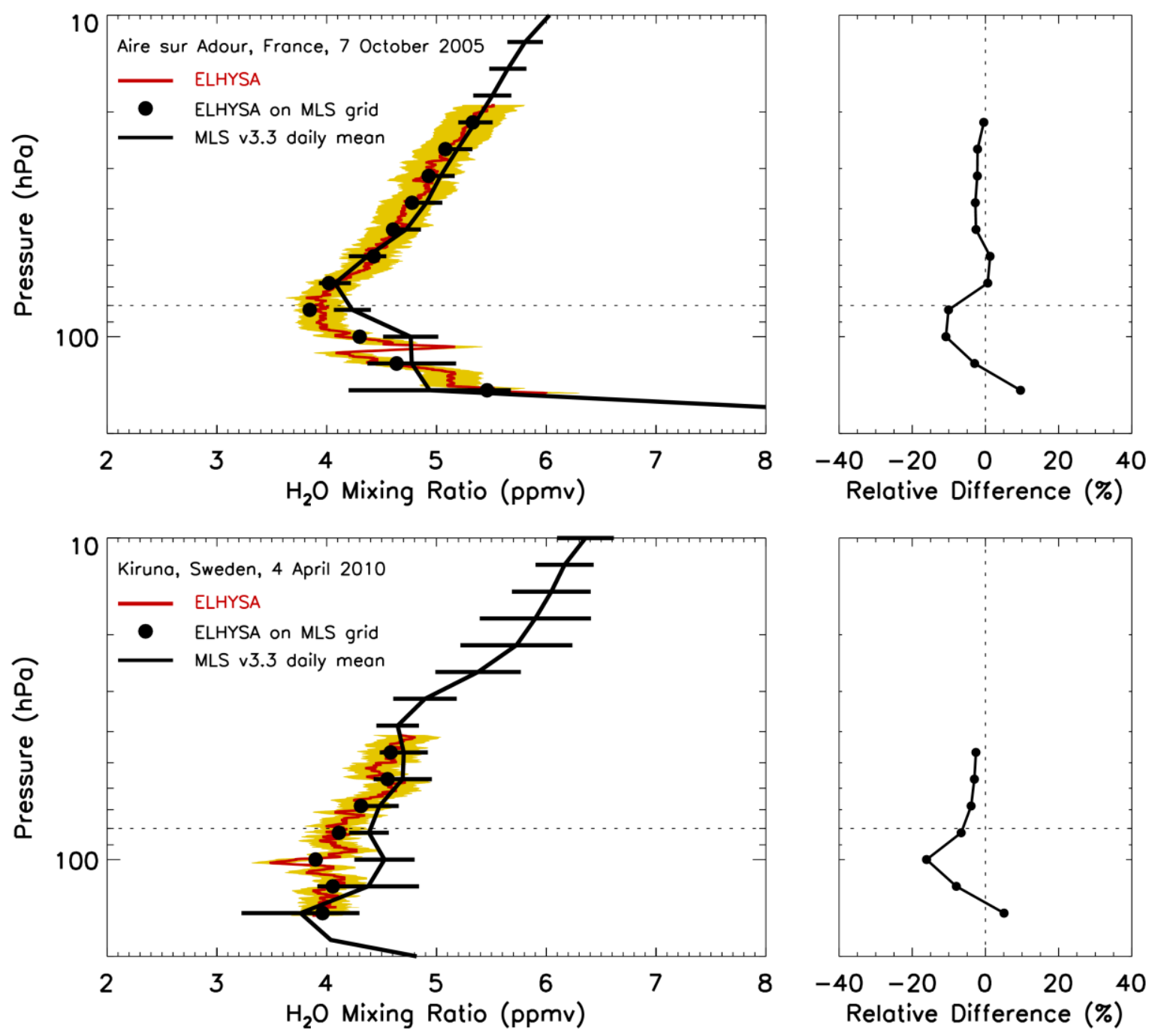

Figure 6: Vertical profiles of water vapour observed by the ELHYSA frost point hygrometer on 7 October 2005 at the Aire sur l'Adour mid-latitude site (top) and on 4 April 2010 at the Kiruna high-latitude site (bottom) and compared to MLS observations. The high-resolution balloon profile (red line) has been degraded to obtain a low resolution profile (full circles) corresponding to the vertical resolution of MLS. The daily-averaged MLS profiles (black line) have been obtained after application of the PV method (see text). 

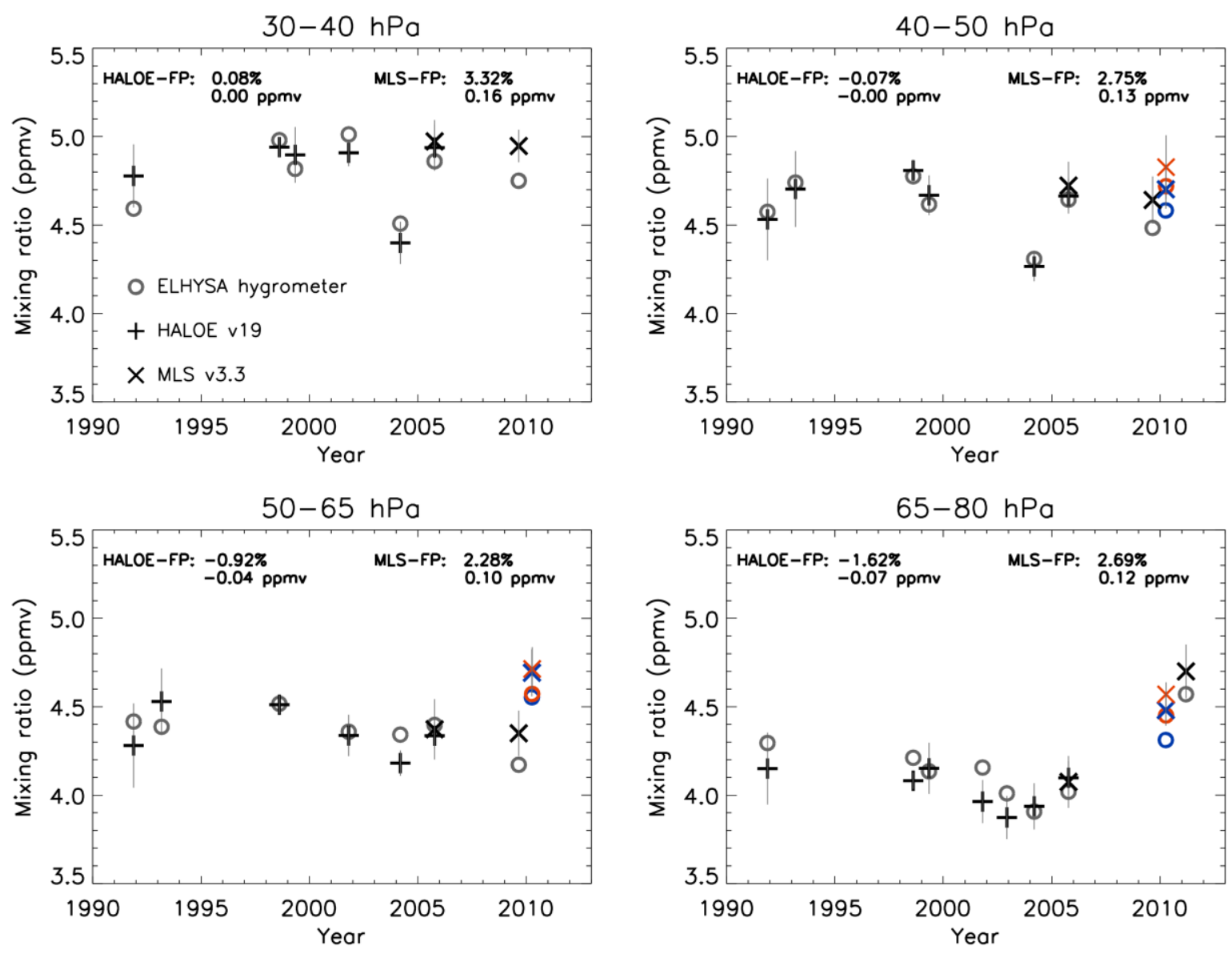

Figure 7: Water vapour mixing ratios from ELHYSA (circles) and coincident satellite observations with HALOE v19 (plus signs) and MLS v3.3 (crosses) data available for the 1991-2005 and 2005-2011 periods respectively. All data have been PV-sorted using the method described in the text and binned within 4 selected pressure ranges (30-40, 40-50, 5065 and 65-80 hPa). ELHYSA high resolution data have been vertically averaged over each pressure range for comparison with HALOE. The ELHYSA mixing ratio values degraded to the resolution of MLS as shown in Figure 6 are used for comparison with MLS in each vertical bin. Error bars on each satellite point represent the 1-sigma standard deviation. The data in blue and red represent the cases of 4 and 9 April 2010 respectively. Percentage values given in each plot correspond to the mean differences between balloon and satellite values (FP is for the ELHYSA Frost Point instrument). For the 2005 case, the figure does not reflect the expected bias between HALOE v19 and MLS v3.3 data certainly as a result of the time 
lag between both sets of available profiles (no HALOE data are available to meet the time coincidence criterion with the October 2005 balloon observations, see text).

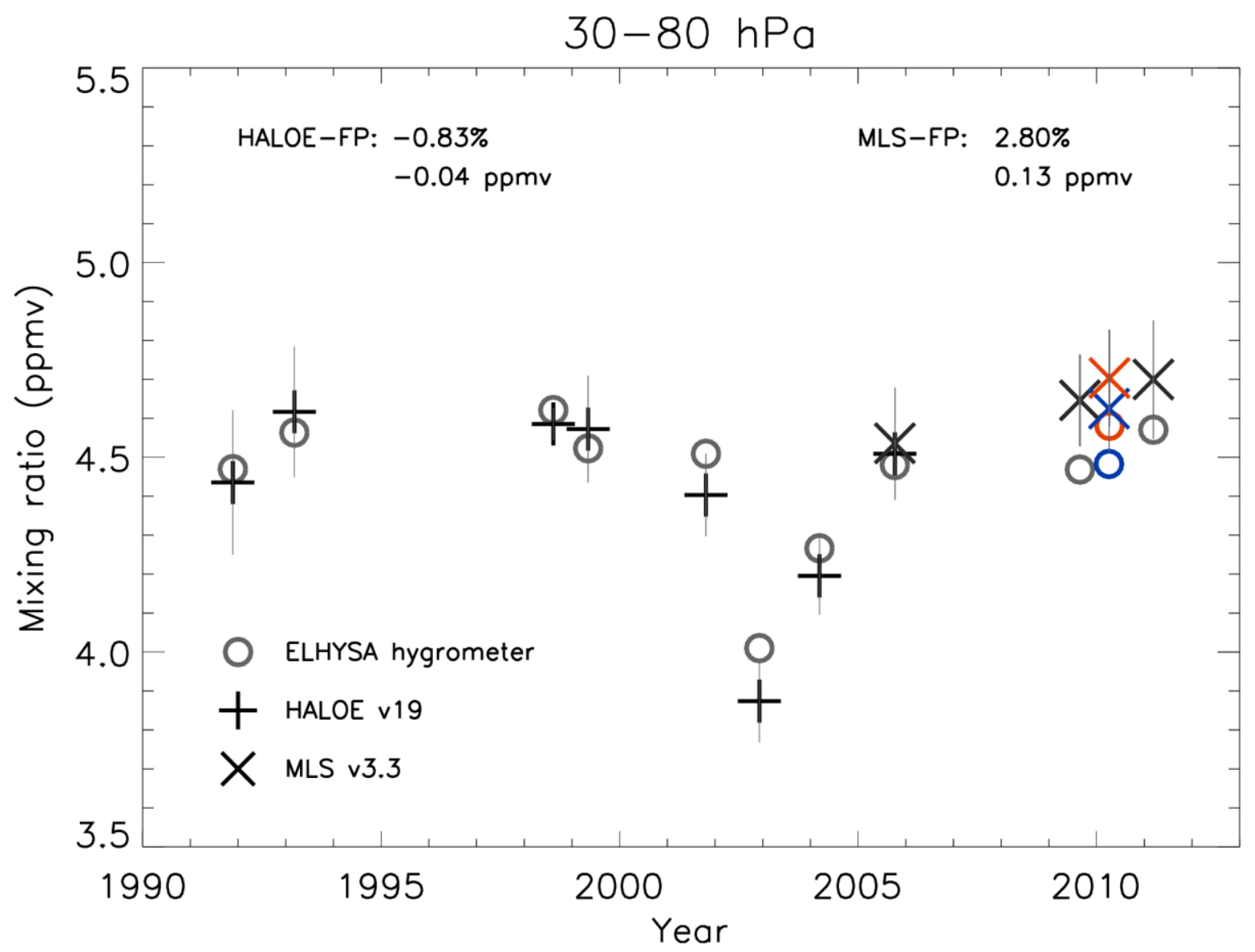

Figure 8: Same as Figure 7 but with the PV selection method and averaging applied to the whole 30-80 hPa range. 


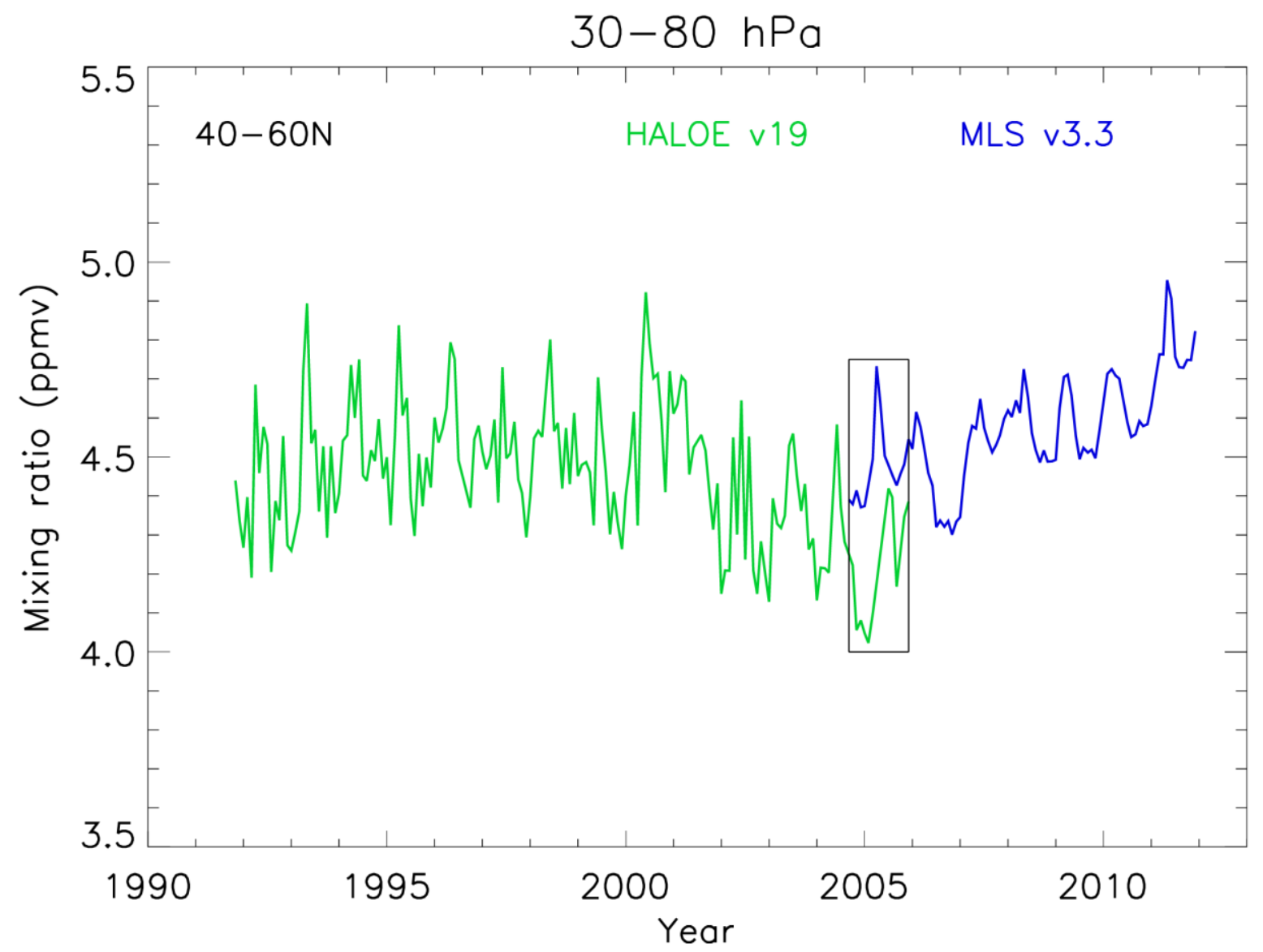

Figure 9: Time series of monthly-mean stratospheric water vapor at mid-latitudes $\left[40^{\circ} \mathrm{N}\right.$ $60^{\circ} \mathrm{N}$ ] from HALOE v19 (green) and MLS v3.3 (blue) satellite data for the 30-80 hPa vertical range. HALOE and MLS datasets have been represented on the same plot to figure out and discuss the bias between both instruments over their period of overlap (black rectangle). 